Review

\title{
From Riluzole to Dexpramipexole via Substituted-Benzothiazole Derivatives for Amyotrophic Lateral Sclerosis Disease Treatment: Case Studies
}

\author{
Serge Mignani ${ }^{1,2, *}$, Jean-Pierre Majoral ${ }^{3,4}$, Jean-François Desaphy ${ }^{5}\left(\mathbb{D}\right.$ and Giovanni Lentini ${ }^{6, *}$ (i) \\ 1 Laboratoire de Chimie et de Biochimie Pharmacologiques et Toxicologique, Université Paris Descartes, \\ PRES Sorbonne Paris Cité, CNRS UMR 860, 45, rue des Saints Peres, 75006 Paris, France \\ 2 CQM-Centro de Química da Madeira, MMRG, Universidade da Madeira, Campus da Penteada, \\ 9020-105 Funchal, Portugal \\ 3 Laboratoire de Chimie de Coordination du CNRS, 205 route de Narbonne, 31077 Toulouse CEDEX 4, France; \\ jean-pierre.majoral@lcc-toulouse.fr \\ 4 Université Toulouse, 118 route de Narbonne, 31077 Toulouse CEDEX 4, France \\ 5 Dipartimento di Scienze Biomediche e Oncologia Umana, Scuola di Medicina, Università degli Studi di Bari \\ Aldo Moro, Piazza Giulio Cesare, 70124 Bari, Italy; jfdesaphy@gmail.com \\ 6 Dipartimento di Farmacia-Scienze del Farmaco, Università degli Studi di Bari Aldo Moro, via Orabona 4, \\ 70125 Bari, Italy \\ * Correspondence: serge.mignani@parisdescartes.fr (S.M.); giovanni.lentini@uniba.it (G.L.); \\ Tel.: +33688069293 (S.M.); +390805442744 (G.L.)
}

Academic Editor: Derek J. McPhee

Received: 28 June 2020; Accepted: 21 July 2020; Published: 22 July 2020

\begin{abstract}
The 1,3-benzothiazole (BTZ) ring may offer a valid option for scaffold-hopping from indole derivatives. Several BTZs have clinically relevant roles, mainly as CNS medicines and diagnostic agents, with riluzole being one of the most famous examples. Riluzole is currently the only approved drug to treat amyotrophic lateral sclerosis (ALS) but its efficacy is marginal. Several clinical studies have demonstrated only limited improvements in survival, without benefits to motor function in patients with ALS. Despite significant clinical trial efforts to understand the genetic, epigenetic, and molecular pathways linked to ALS pathophysiology, therapeutic translation has remained disappointingly slow, probably due to the complexity and the heterogeneity of this disease. Many other drugs to tackle ALS have been tested for 20 years without any success. Dexpramipexole is a BTZ structural analog of riluzole and was a great hope for the treatment of ALS. In this review, as an interesting case study in the development of a new medicine to treat ALS, we present the strategy of the development of dexpramipexole, which was one of the most promising drugs against ALS.
\end{abstract}

Keywords: riluzole; amyotrophic lateral sclerosis (ALS); dexpramipexole; 1,3-benzothiazole (BTZ); indoles; DrugBank; chronic neurodegenerative disorders

\section{Introduction}

Bicyclic heterocyclic structures are commonly found both in natural and synthetic biologically relevant compounds with indole are probably the most widespread scaffold of this type. In Nature, the indole nucleus may be found in neurotransmitters and autacoids such as serotonin, melatonin, and melanin, which derive from the corresponding amino acid tryptophan, and in a plethora of alkaloids. Dozens of synthetic routes have been developed to afford thousands of compounds based on the indole scaffold [1,2] and more than 300 indole-based small molecules can be found in DrugBank [3]. However, the functionalization of the indole ring may be somewhat limited by its innate nucleophilicity [4], 
with its relatively high HOMO energy allowing mainly for electrophilic substitution at the 3-position. The same electronic distribution that biases scaffold decoration is the cause of the relative metabolic instability of indole-derived drugs [5] and may confer potential for pan assay interference [6] and host-gut microbiota metabolic interactions [7]. In some instances, the NH hydrogen bond donor group might be unnecessary or even detrimental when binding requirements are to be fulfilled. For all above reasons, scaffold-hopping from indole to a suitable equivalent ring [8] may be advisable, with the 1,3-benzothiazole (BTZ) ring being a relatively less explored alternative [9-12]. In Table 1, a comparison of the main physicochemical features of the two bicyclic systems is reported and a clear-cut electron density complementarity emphasizes each other's qualities. Due to its low energy LUMO, BTZ mainly undergoes nucleophilic substitution with the 2-position being preferred, as suggested by its LUMO density distribution. Scaffold-hopping to BTZ should be considered when plasma protein binding is advisable. Plasma protein binding has a strong nonspecific component with the size of drugs playing a major role [13]. Considering both BTZ's relatively higher metabolic stability and affinity for plasma proteins, the BTZ scaffold should afford longer activity duration.

Table 1. Main physicochemical features of indole and 1,3-benzothiazole rings.

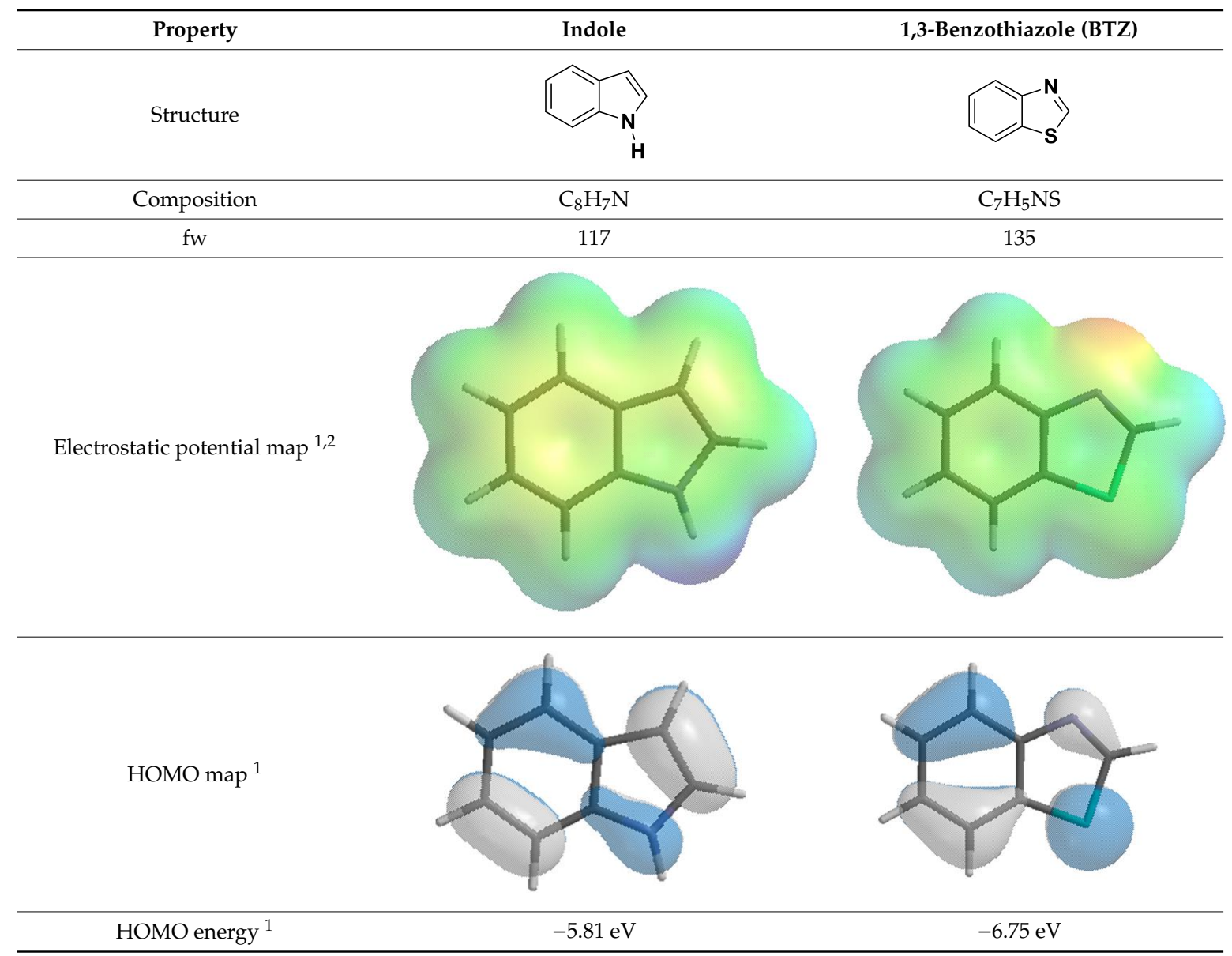


Table 1. Cont.

\begin{tabular}{ccc}
\hline Property & Indole & 1,3-Benzothiazole (BTZ) \\
\hline LUMO map $^{1}$ & $-0.61 \mathrm{eV}$ & $-1.38 \mathrm{eV}$ \\
\hline LUMO energy $^{1}$ & - & 1 \\
\hline $\mathrm{HBA}^{3}$ & 1 & 2.14 \\
\hline $\mathrm{HBD}^{4}$ & 2.01 \\
\hline $\operatorname{cLg}^{5}$ & & \\
\hline
\end{tabular}

${ }^{1}$ Calculated at the DFT B3LYP/6-311+G(2df,2p)//DFT B3LYP/6-311+G(2df,2p) level. [14] ${ }^{2}$ Warm colors indicate relatively high electron density with red color corresponding to the highest electron density regions; cold colors indicate relatively low electron density with blue color corresponding to the lowest electron density regions. ${ }^{3} \mathrm{HBA}$, hydrogen bond acceptor. ${ }^{4} \mathrm{HBD}$, hydrogen bond donor. ${ }^{5} \mathrm{ACD} /$ Labs 7.0 .

The substitutions of the BTZ scaffold have shown a broad range of biologic activities, including anti-infective [15], anti-inflammatory [16], antitumor [17], antimyotonic [18], anticonvulsant [19], and neuroprotective properties in both acute and chronic models of neurodegeneration [20]. The approved (A), investigational (I), experimental (E), and withdrawn (W) BTZ derivatives reported in DrugBank [3] are captured in Figures 1 and 2.

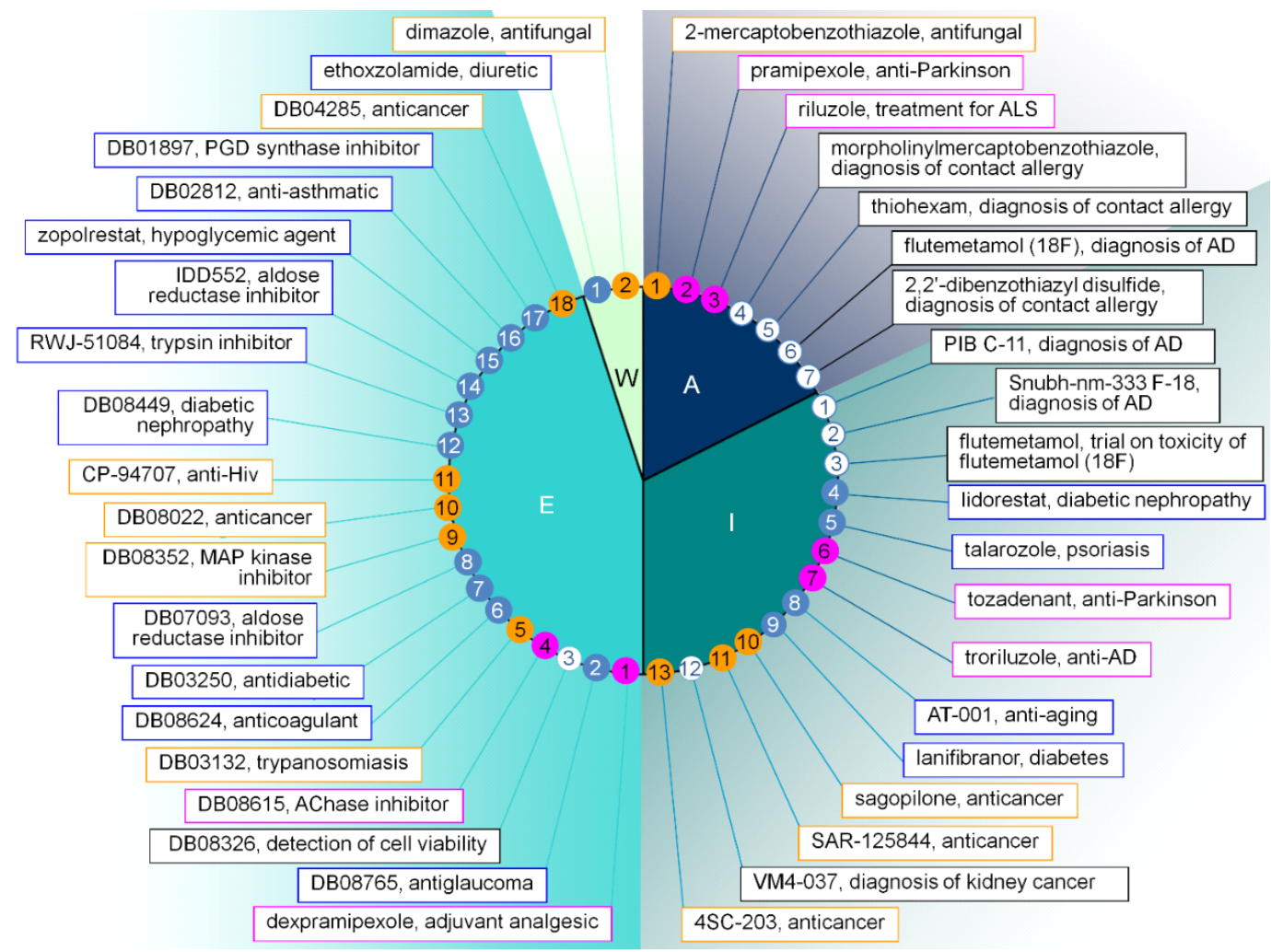

Figure 1. Common names and therapeutic applications of the 1,3-benzothiazole drugs included in DrugBank [3]; A: approved, I: investigational, E: experimental, W: withdrawn; each drug has been color-coded as follows: yellow = etiotropic agent, magenta = drugs acting on CNS, white = diagnostic, and blue $=$ pharmacodynamic agent (see text for details) . 


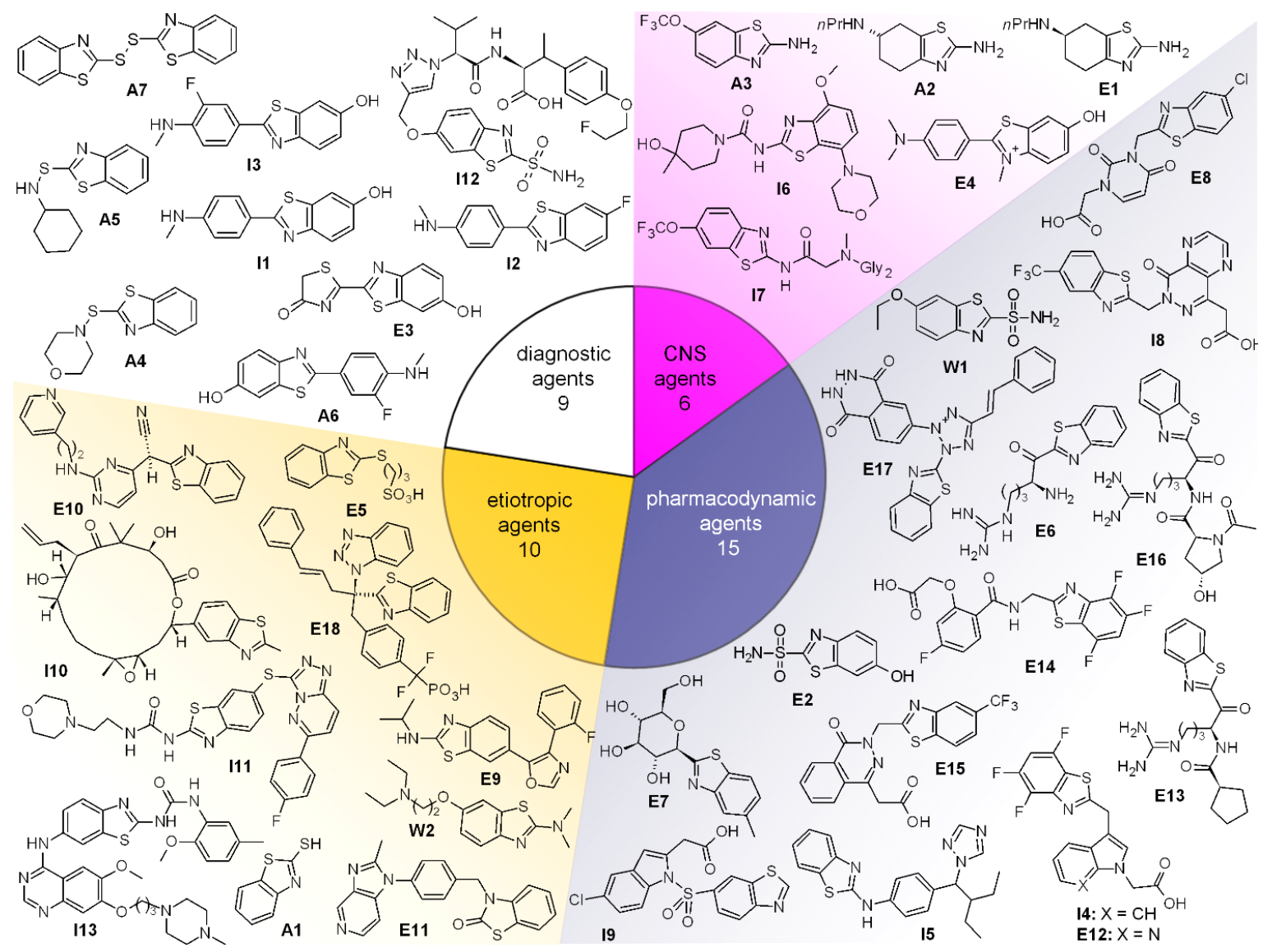

Figure 2. Structures and classes of the 1,3-benzothiazole drugs included in DrugBank ${ }^{3}$; A: approved, I: investigational, E: experimental, W: withdrawn; each therapeutic class has been color-coded as follows: yellow = etiotropic agent, magenta = drugs acting on CNS, white $=$ diagnostic, and blue = pharmacodynamic agent (see text for details).

For the sake of simplicity, four main groups of drugs were considered. Anticancer, antiprotozoal, antifungal, antibacterial, and antiviral activities were generally referred to as etiotropic activities

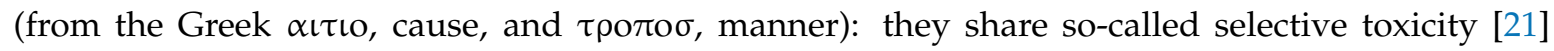
against the unwanted guest (the aggressor) as their basic mechanism with the assumption that cancer cells are no longer considered self-cells. They were color-coded yellow. Both neurological and psychiatric drugs were generally referred to as drugs acting on CNS and magenta is the corresponding color code. They include drugs to alleviate amyotrophic lateral sclerosis (ALS) and anti-Parkinson, anti-Alzheimer, anticonvulsant, analgesic, and antidepressant agents. Diagnostic agents are color-coded white and, finally, all other classes of drugs were included in the general group of pharmacodynamic agents (color-coded blue): they modify autonomic body functions and include antidiabetic, anti-inflammatory, antioxidant, antiallergic, antipsoriasis, and antihypertensive agents. The aforementioned regioselectivity bias which favors substitution onto the 2-position is highlighted in Figure 3. In Figures 4 and 5, more details are given about the substituents found in A and I drugs reported in DrugBank, respectively. 


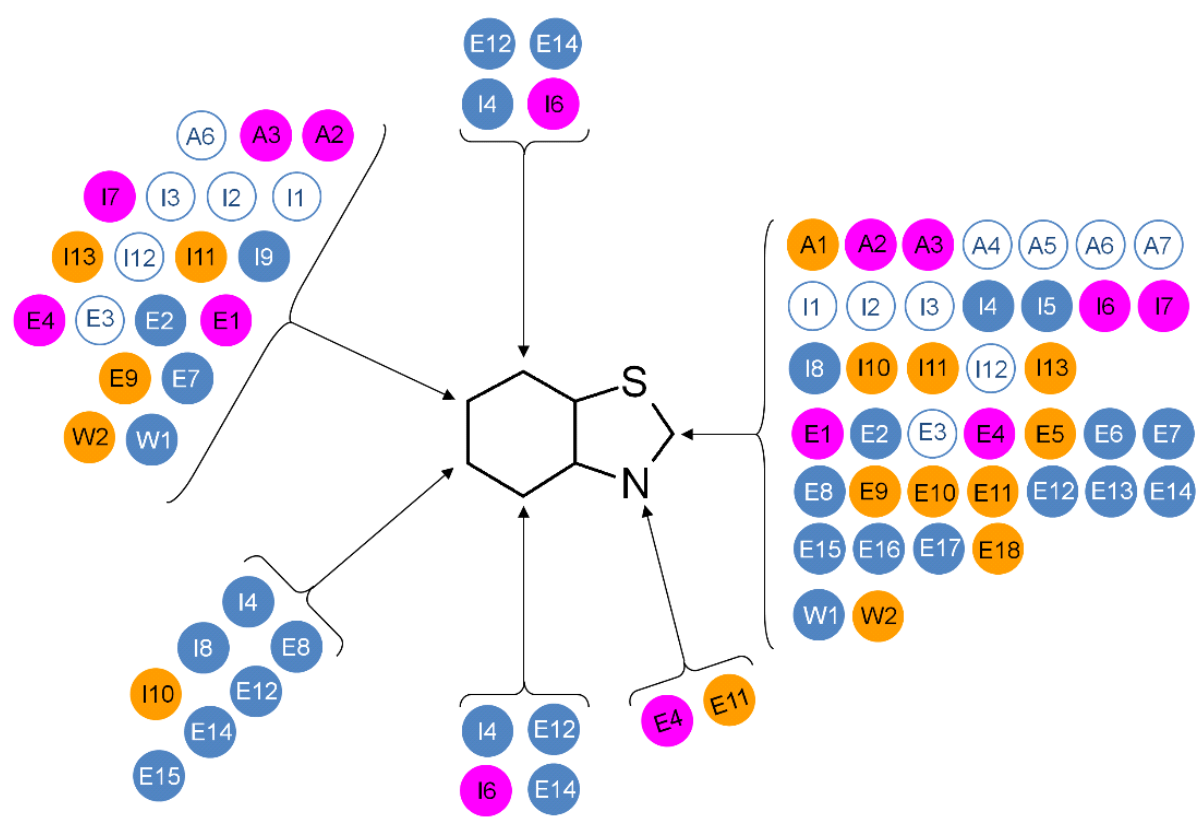

Figure 3. Patterns of substitution displayed by the 1,3-benzothiazole drugs included in DrugBank [3]; A: approved, I: investigational, E: experimental, W: withdrawn; each therapeutic class has been color-coded as follows: yellow = etiotropic agent, magenta = drugs acting on CNS, white = diagnostic, and blue $=$ pharmacodynamic agent (see text for details) .

\section{Approved drugs (A)}

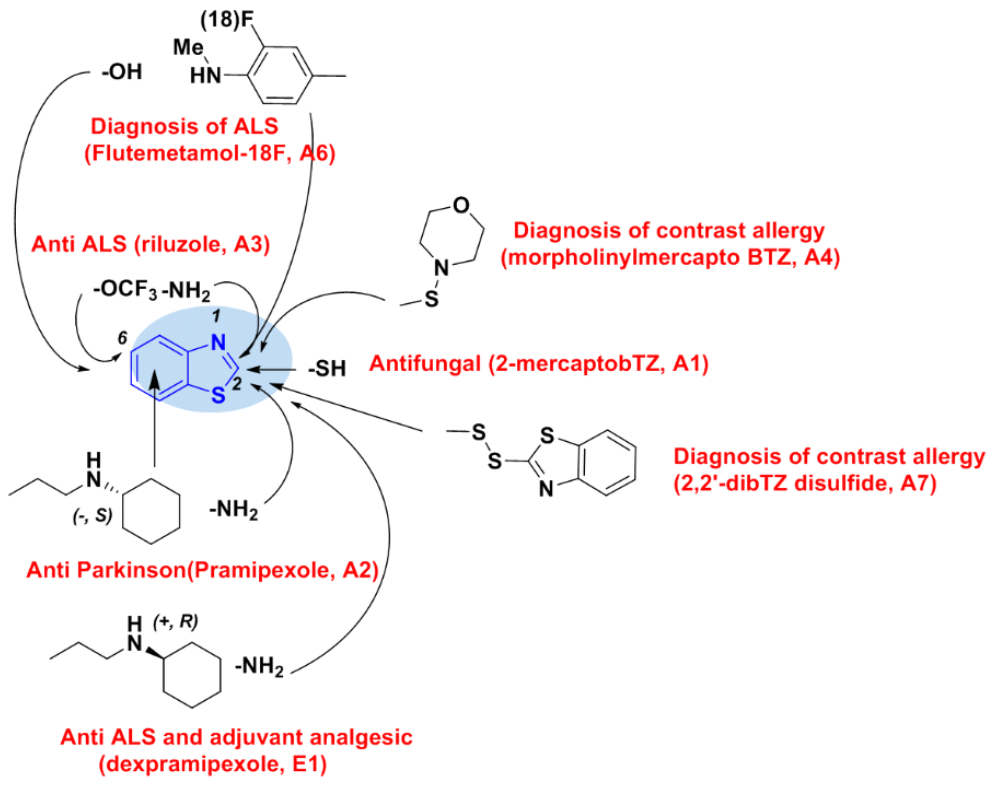

Figure 4. Substituents displayed by the approved 1,3-benzothiazole drugs included in DrugBank [3]; dexpramipexole (E1) was included. 


\section{Investigational drugs (I)}

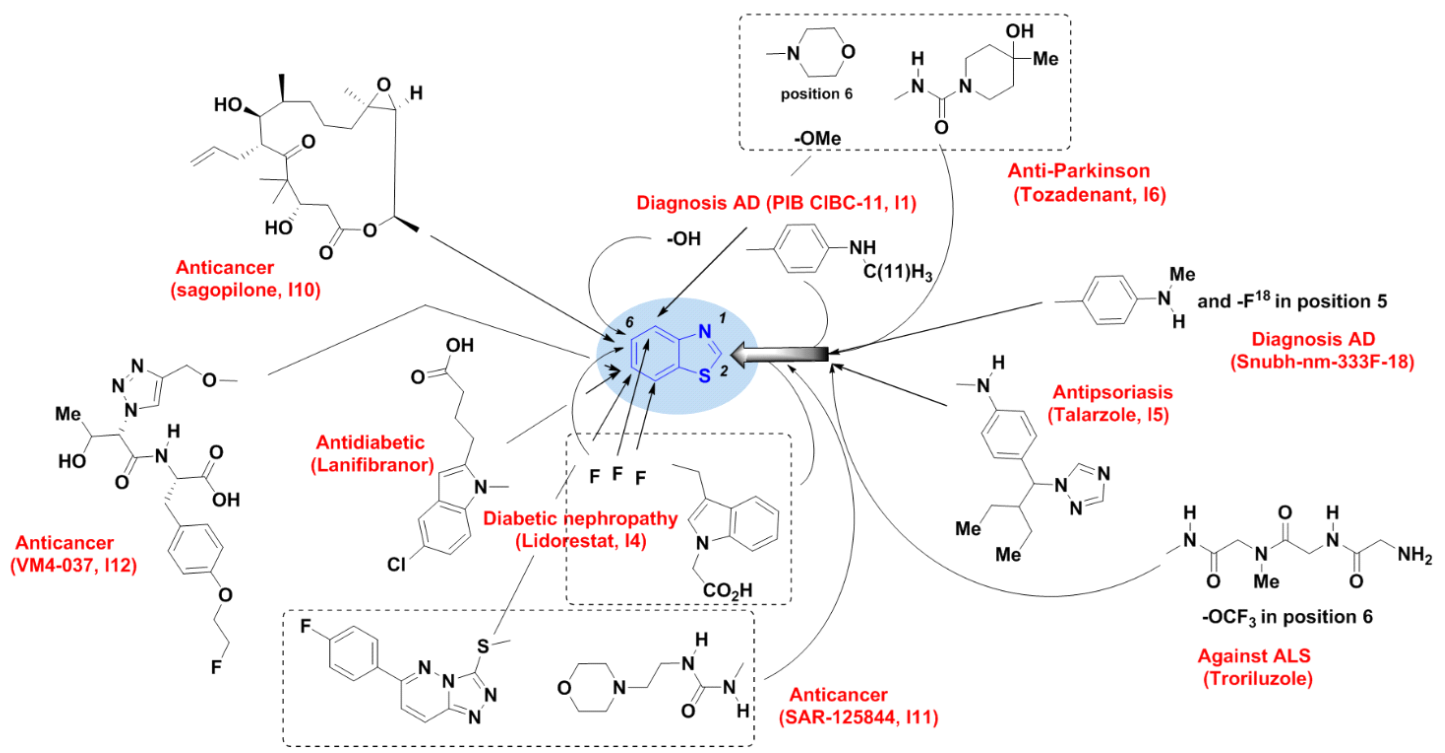

Figure 5. Substituents displayed by the investigational 1,3-benzothiazole drugs included in DrugBank [3].

With few exceptions, the BTZ derivatives reported in DrugBank fulfil the requirements for high oral bioavailability (Table 2) [22] with the most interesting compounds being the riluzole (A3) analog pramipexole (A2) and its enantiomer dexpramipexole (E1). A2 and E1 present relatively high 3D structural complexity (they are optically active compounds endowed with a high fraction of $\mathrm{sp}^{3}$ carbon atoms) [23] and due to their low molecular weight may be considered as fragments (Ro3 fulfilled).

Table 2. Good-quality criteria applied to 1,3-benzothiazole drugs included in DrugBank [3].

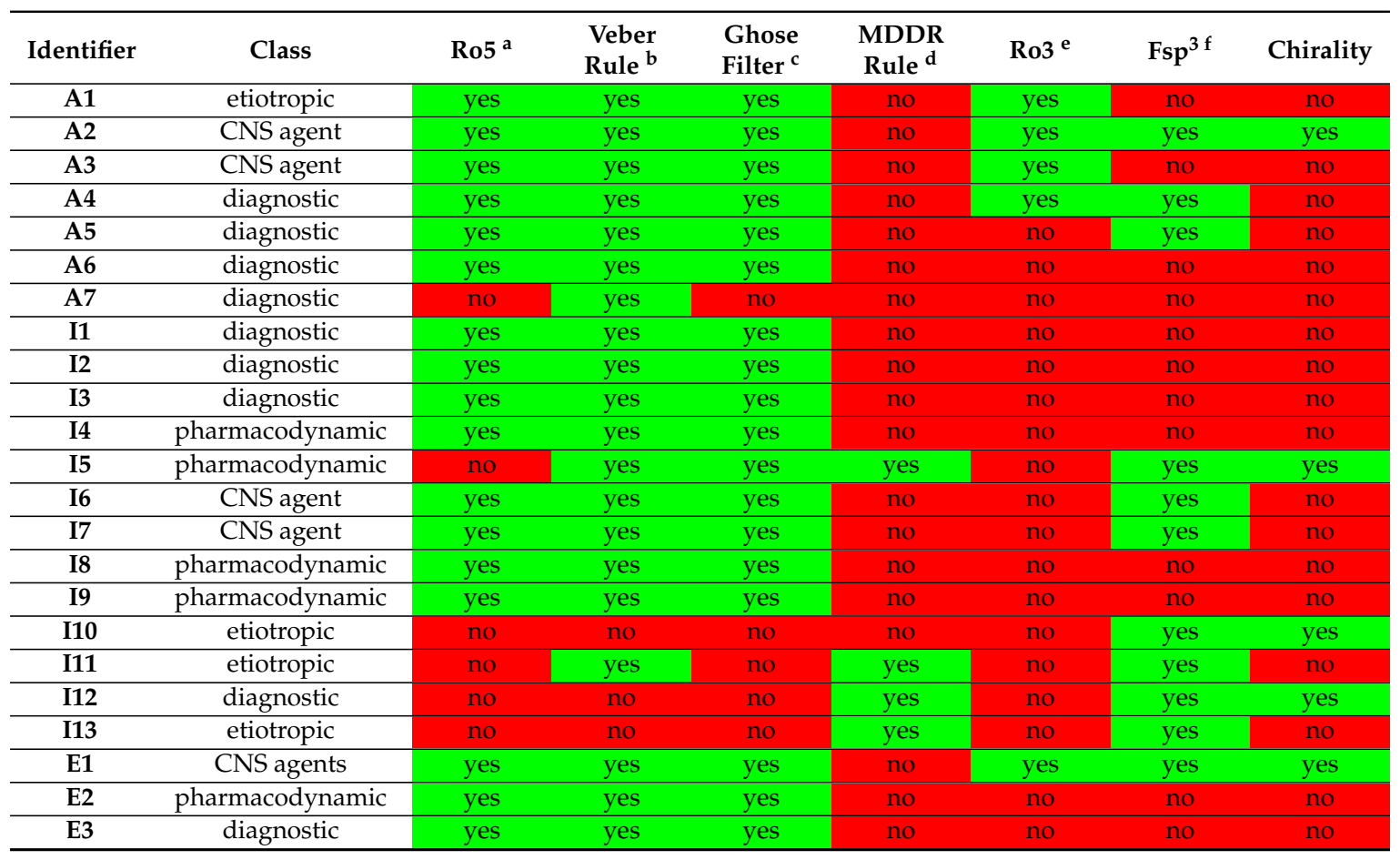


Table 2. Cont.

\begin{tabular}{|c|c|c|c|c|c|c|c|c|}
\hline Identifier & Class & $\operatorname{Ro5}^{a}$ & $\begin{array}{l}\text { Veber } \\
\text { Rule }^{\text {b }}\end{array}$ & $\begin{array}{l}\text { Ghose } \\
\text { Filter }\end{array}$ & $\begin{array}{c}\text { MDDR } \\
\text { Rule }^{\text {d }}\end{array}$ & $\operatorname{Ro3}^{\mathrm{e}}$ & $\mathrm{Fsp}^{3 \mathrm{f}}$ & Chirality \\
\hline $\mathrm{E} 4$ & CNS agent & yes & yes & yes & no & no & no & no \\
\hline E5 & etiotropic & yes & yes & yes & no & no & yes & no \\
\hline E6 & pharmacodynamic & yes & yes & yes & no & no & yes & yes \\
\hline E7 & pharmacodynamic & yes & yes & yes & no & no & yes & yes \\
\hline E8 & pharmacodynamic & yes & yes & yes & no & no & no & no \\
\hline E9 & etiotropic & yes & yes & yes & no & no & no & no \\
\hline E10 & etiotropic & yes & yes & yes & no & no & no & yes \\
\hline E11 & etiotropic & yes & yes & yes & no & no & no & no \\
\hline E12 & pharmacodynamic & yes & yes & yes & no & no & no & no \\
\hline E13 & pharmacodynamic & yes & yes & yes & no & no & yes & yes \\
\hline E14 & pharmacodynamic & yes & yes & yes & no & no & no & no \\
\hline E15 & pharmacodynamic & yes & yes & yes & no & no & no & no \\
\hline E16 & pharmacodynamic & yes & no & no & no & no & yes & yes \\
\hline E17 & pharmacodynamic & yes & yes & no & yes & no & no & no \\
\hline E18 & etiotropic & no & yes & no & yes & no & no & yes \\
\hline W1 & pharmacodynamic & yes & yes & yes & no & no & yes & no \\
\hline W2 & etiotropic & yes & yes & yes & no & no & yes & no \\
\hline
\end{tabular}

${ }^{a}$ Rule of Five: hydrogen bond donors (HBDs) $\leq 5$, hydrogen bond acceptors (HBAs) $\leq 10, \mathrm{MW} \leq 500 \mathrm{Da}, \operatorname{cLog} P \leq$ 5 [24]; b polar surface area (PSA) $\leq 140 \AA^{2}$, rotatable bonds (RBs) $\leq 10, \mathrm{HBDs}+\mathrm{HBAs} \leq 12$ [25]; ${ }^{\mathrm{c}}-0.4<\operatorname{cLog} P<5.6$, $160<$ MW $<480,40<$ molar refractivity $(\mathrm{MR})<130,20<$ number of atoms $<70$ [26]; ${ }^{\mathrm{d}}$ MACCS-II Drug Data Report (MDDR)-like rule: ring number (RN) $\geq 3$, RBs $\geq 6$, rigid bonds $(\mathrm{RBs}) \geq 18$ [27]; ${ }^{\mathrm{e}}$ Rule of Three: hydrogen bond donors (HBDs) $\leq 3$, hydrogen bond acceptors (HBAs) $\leq 3, \mathrm{MW}<300 \mathrm{Da}, \operatorname{cLog} P \leq 3$ [28]; ${ }^{\mathrm{f}}$ fraction of $\mathrm{sp}^{3}$ hybridized carbon atoms (i.e., number of $\mathrm{sp}^{3}$ hybridized carbons/total carbon count) $>0.2$. [29].

Despite some contrasting considerations [30,31], high plasma protein binding is generally considered as a factor that possibly limits CNS distribution and reduces potency at that level [32]. CNS penetration decreases as molecular weight increases [33]. The same detrimental effect on blood-brain barrier penetration stems from hydrogen bond acceptor groups [34]. Thus, it might be expected that the BTZ scaffold should be relatively unsuitable for drugs that would act on CNS. Curiously, the most interesting BTZ derivatives—riluzole (A3), pramipexole (A2) and dexpramipexole (E1)—display their activities on the CNS. Probably, an optimized lipophilic balance compromises with features that are detrimental to brain distribution [34]. In this review, we present the strategy of the development of dexpramipexole, which was one of the most promising drugs against ALS and is now under study as an adjuvant analgesic.

\section{Treatments against Chronic Neurodegenerative Disorders}

The development of treatments against chronic neurodegenerative disorders such as Alzheimer's (AD) and Parkinson's (PD) diseases, as well as amyotrophic lateral sclerosis (ALS; also known as Lou Gehrig's disease or Charcot's sclerosis), and acute conditions such as brain ischemia and trauma have proven extremely difficult. Among others, these diseases are connected with the excitotoxicity of excitatory amino acids (EAAs) as neurotransmitters [35]. Excessive release of glutamate and a subsequent over activation of excitatory amino acid receptors such as $N$-methyl-d-aspartate (NMDA), $\alpha$-amino-3-hydroxy-5-methyl-4-isoxazolepropionic acid (AMPA), and ainite receptors represent the main steps of the excitotoxic cascade. These attractive targets have been studied for the development of neuroprotective agents. A very interesting class of neuroprotective agents is represented by a simple benzothiazole ring as a scaffold. One of them is riluzole (Rilutek ${ }^{\circledR}$, 2-amino-6-(trifluoromethoxy)benzothiazole, Figure 6), which has demonstrated neuroprotective effects in several animal models of PD [36], Huntington's disease [37] and cerebral ischemia [38]. Riluzole is currently the only Food and Drug Administration (FDA)-approved drug for the treatment of ALS. The drug prolongs survival time by a few months and delays the use of invasive supportive therapies, such as mechanical ventilation and tracheotomy, but shows little efficacy on muscle strength or function [39-43]. Riluzole is a nonspecific neuroprotectant. 

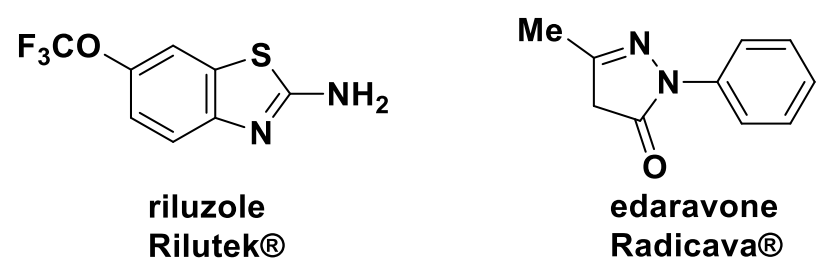

Figure 6. Chemical structure of riluzole (Rilutek ${ }^{\circledR}$ ) and edaravone (Radicava ${ }^{\circledR}$ ).

Radicava $($ (edaravone, Figure 6), with antioxidant properties, was approved for the treatment of ALS in Japan (2015) and in the United States (2017). In 2015, the drug was designated an orphan medicine for ALS by the European Medicine Agency. However, on 24 May 2019, Mitsubishi Tanabe Pharma GmbH formally notified the Committee for Medicinal Products for Human Use (CHMP) of its wish to withdraw its marketing authorization application for the treatment of ALS due to unfavorable benefit risk balance [44]. This withdrawal did not have impact on the ongoing clinical trials with Radicava ${ }^{\circledR}$. The chemical structure of edaravone (5-methyl-2-phenyl-2,4-dihydro-3H-pyrazol-3-one) is different from that of riluzole.

To date, the causes of ALS, both familial ( 10\%) and sporadic ( $90 \%)$, are unknown, except for a small number of inherited monogenic cases. ALS is universally fatal, characterized by progressive weakness [45] due to the degeneration of upper and lower spinal motor neurons, and leads eventually to respiratory failure, which is the usual cause of death. The major proposed mechanisms of ALS are glutamate excitotoxicity, oxidative stress, mitochondrial dysfunction, protein aggregation, superoxide dismutase 1 (SOD1) accumulation and neuronal death [46].

In early clinical trials with 876 ALS patients receiving riluzole compared to 406 patients receiving placebo, riluzole showed an increase in mean survival time, varying from 3 months (dose, $100 \mathrm{mg} /$ day) to 1.7 months (various dose levels) [41].

Riluzole was developed by the Pharmuka Laboratoires (Antony, France) in the 1980s under the reference PK 26124. Pharmuka Laboratoires became Rhône-Poulenc Rorer (Antony, France) in 1983, now named Sanofi. Riluzole was found using a phenotypic screening strategy and was shown to be capable of interfering with the mechanisms of neuronal death in the ALS. Currently, the drug is marketed by Sanofi under the brand name Rilutek ${ }^{\circledR}$. In 2012, it became available as a generic drug.

Riluzole was first tested in the early 1980s as an antiepileptic, based for example, on its action to prevent rodent convulsions induced by electroshock, $\gamma$-aminobutyric acid (GABA) synthesis inhibitors, or ouabain. This anticonvulsant activity was not due to an effect on GABAergic neurotransmission, as with other classical treatments, but relied on an antagonistic action against neurotransmission by certain excitatory amino acids. A few years later, riluzole was included in experimental models broader than those just for epilepsy, such as ischemia. It was shown that, as expected from its antiglutamatergic activity, riluzole decreased neuronal death due to ischemia. This antiglutamatergic action appeared quite peculiar, because riluzole does not bind to any of the known excitatory amino acid receptors but appears to act primarily at the presynaptic level, blocking the release of glutamate. The results of the first clinical trial for the treatment of ALS by riluzole, involving 155 patients and carried out in double-blind, showed an effect on patient survival. The data was even better for the bulbar form of ALS, which is rarer.

Generally speaking, several speculative mechanisms of action of riluzole have been proposed, including the inhibition of voltage-gated sodium channels, which can reduce neurotransmitter release, noncompetitive inhibition of NMDA receptors [47], inhibition of glutamate release [48], and enhanced astrocytic uptake of extracellular glutamate [49]. Experiments with animal models of excitotoxicity and injury demonstrated that riluzole plays an important role as a neuroprotective agent [50]. In addition, riluzole is known also to be an antioxidant agent [51], an antiapoptotic agent [51] and has beneficial effects on neuronal cell death due to cisplatin-induced ototoxicity [52].

There are an increasing number of patients diagnosed with ALS with an incidence between 0.6 and 3.8 per 100,000 people/year in the World. The incidence is higher in Europe, between 2.1 and 
3.8 per 100,000 people/year. Recent studies have reported a prevalence of ALS between 4.1 and 8.4 per 100,000 people. In addition, a difference in ALS prevalence by ethnicity was reported in the United States [53]. Consequently, the need to find new alternatives to the current single treatment using riluzole is becoming increasingly urgent in order to treat ALS-affected patients.

The purpose of this manuscript is to review the development of dexpramipexole for the treatment of ALS. It should be noted that this structural analog of riluzole, was not synthesized to mimic the efficacy of riluzole in ALS by exploiting its structural similarity [54]. In this respect, the origin of dexpramipexole development differs from the one of the monosubstituted 2-benzo-thiazolamines and 3-substituted 2-iminobenzothiazoline derivatives developed by Rhône-Poulenc Rorer (Vitry-sur-Seine center, Vitry-sur-Seine, France) [55] and, recently, by Sweeney et al. from the University of Bradford (Bradford, UK) [56]. To the best of our knowledge, two drug therapies have been developed in the clinical phase to fight ALS, the FDA-approved riluzole and dexpramipexole, which represents an interesting case study in that is chemically close to riluzole. Riluzole and its SARs were mainly developed in Rhône-Poulenc/Aventis in Vitry-sur-Seine research center (France). Other potential drugs against ALS are the hydroxylamine arimoclomol [57], the noncompetitive AMPA agonist perampanel [58], the beta-lactam antibiotic ceftriaxone [59], the free-radical scavenger bromocriptine [60], and the non-steroidal anti-inflammatory nimesulide [61]. Other strategies to tackle ALS are stem cell therapy [62] and immunotherapy [63].

\section{6-Substituted 2-Benzothiazolamines and 3-Substituted 2-Iminobenzothiazoline Derivatives as Analogues of Riluzole}

In the 1950s, the major studies regarding the development of 2-benzothiazolamines were dedicated to central muscle relaxants [64]. Then, riluzole had shown interesting neuroprotective slowing ALS progression in clinical trials (vide supra). Taking advantages of these important studies, two series of close analogues of riluzole were prepared by Mignani's teams in Rhône-Poulenc Rorer in the 90s: 6-substituted 2-benzothiazolamines and 3-substituted 2-iminobenzothiazolines (Figure 7) [55]. All of these riluzole analogues were tested in vivo (ip administration) for the protection against glutamic acid evoked convulsions in rats as a model of neuroprotection. One advantage of this in vivo model is that it takes account of the anticonvulsant effects related to the bioavailability of each compound.

$\mathrm{F}_{3} \mathrm{CO}$<smiles>Cc1ccc2nc(N)sc2c1</smiles>

riluzole

Rilutek $^{R}$

Sanofi

(ante Rhône-Polenc Rorer)

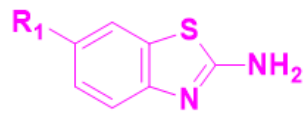

6-substituted2-benzothiazolamines

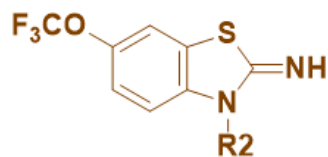

3-substituted-2-imino-

6-

trifluoromethoxybenzothiazolines

Figure 7. Chemical structure of 6-substituted-2-benzothiazolamines and 3-substituted-2-iminobenzothiazolines.

More than 30 6-substituted 2-benzothiazolamines were prepared by one-pot reaction of the corresponding aniline with thiocyanogen generated from bromine and alkaline thiocyanate (Scheme 1) in good yield (> 50\%). 
<smiles>[R]c1ccc(N)cc1</smiles>

\section{4-substituted-anilines}

$$
\begin{aligned}
\mathrm{R}_{1}= & -\mathrm{OCF}_{3} \text { (Riluzole), } \mathrm{H}, \mathrm{F}, \mathrm{CI}, \mathrm{Br}, \mathrm{I},-\mathrm{NH}_{2},-\mathrm{CN} \\
& -\mathrm{CO}_{2} \mathrm{Et},-\mathrm{NO}_{2},-\mathrm{SO}_{2} \mathrm{Me},-\mathrm{OMe},-\mathrm{OtBu},-\mathrm{SiMe}_{3}, \\
& -\mathrm{C}_{6} \mathrm{H}_{11},-\mathrm{Ph},-\mathrm{Me},-\mathrm{Et},-n \mathrm{Pr},-\mathrm{Pr},-n \mathrm{Bu},-n \mathrm{Pen}, \\
& -\mathrm{CH}_{2}-\mathrm{CMe}_{3}, n \mathrm{Hex},-n \mathrm{Hep},-\mathrm{CH}_{2} \mathrm{CF}_{3},-\mathrm{SCF}_{3}, \\
& -\mathrm{OCHF}_{2},-\mathrm{OCH}_{2} \mathrm{C}_{2} \mathrm{~F}_{5},-\mathrm{OCF}_{2} \mathrm{CHF}_{2},-\mathrm{OC}_{2} \mathrm{~F}_{5}, \\
& -\mathrm{C}_{2} \mathrm{~F}_{5},-\mathrm{CF}_{3}
\end{aligned}
$$<smiles>[R7]c1ccc2nc(N)sc2c1</smiles>

6-substituted2-benzothiazolamines

Scheme 1. Synthesis of 6-substituted 2-benzothiazolamines.

More than 40 3-substituted 2-imino benzothiazolines were prepared. As shown in Scheme 2, several synthetic pathways were developed, two starting from 4-trifluoromethoxyaniline and two from riluzole, in moderate to good overall yields [55].
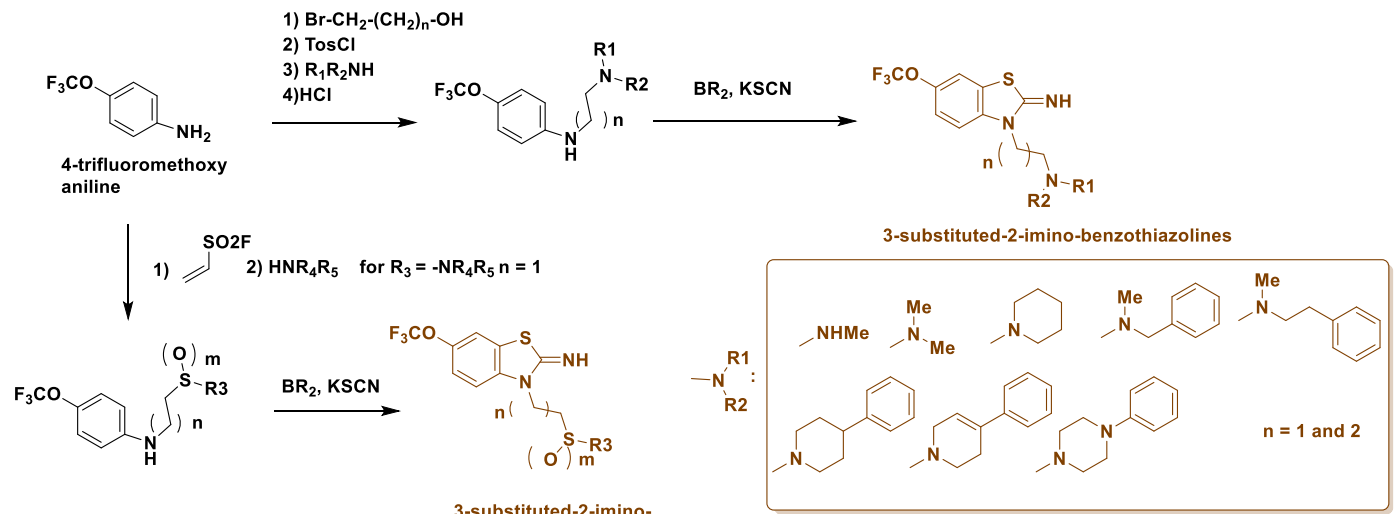

3-substituted-2-imin
benzothiazolines

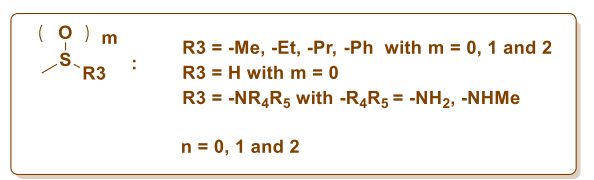

1) $\mathrm{Br}-\mathrm{CH}_{2}-\left(\mathrm{CH}_{2}\right)_{n}-\mathrm{OH}$

2) $\mathrm{CF}_{3} \mathrm{CO}_{2} \mathrm{Et}$

3) $\mathrm{Tos} \mathrm{Cl}$
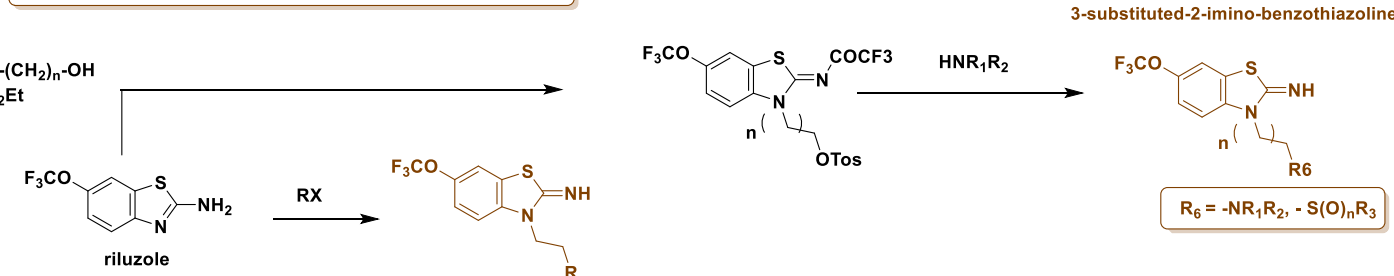

3-substituted-2-imino-benzothiazolines

$\mathrm{R}=-\mathrm{Me},-\mathrm{Et}$, nPropyl, -nbutyl, -allyl, -propargyl, $-\mathrm{CH}_{2} \mathrm{CN},-\mathrm{CH}_{2}-\mathrm{CH}_{2} \mathrm{Ph}$, $\mathrm{CH}_{2} \mathrm{CO}_{2} \mathrm{Me},-\mathrm{CH}_{2}-\mathrm{CONEt}_{2},-\mathrm{CH}_{2}-\mathrm{CONH}_{2},-\mathrm{CH}_{2}-\mathrm{CH}_{2}-\mathrm{OH}$

Scheme 2. 3-Substituted 2-iminobenzothiazolines.

In addition, a small library of simultaneous modifications in positions 3 and 6, and 2 and 3 were prepared using the synthetic pathways described in Schemes 1 and 2 (Figure 8) [55]. 


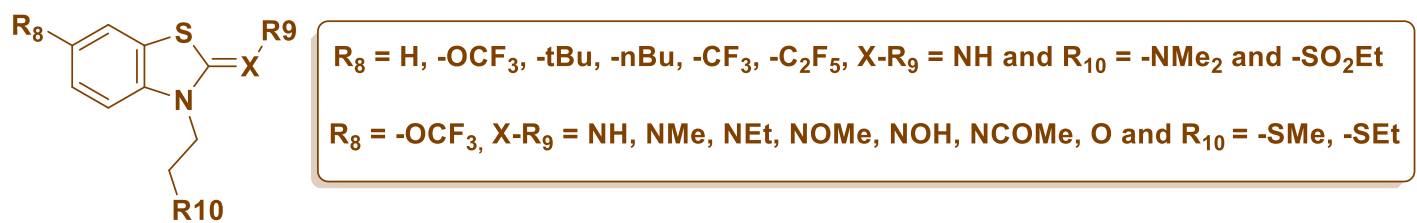

Figure 8. Simultaneous modifications in positions 3 and 6, and 2 and 3.

All of the prepared riluzole analogues were evaluated in two models of neuroprotection: protection against seizures induced by intracerebroventicular administration of glutamic acid in rats and protection against mortality induced by hypobaric hypoxia in mice [55]. The most effective compounds in these models are presented in Table 3.

Table 3. Neuroprotective activities of benzothiazolines.

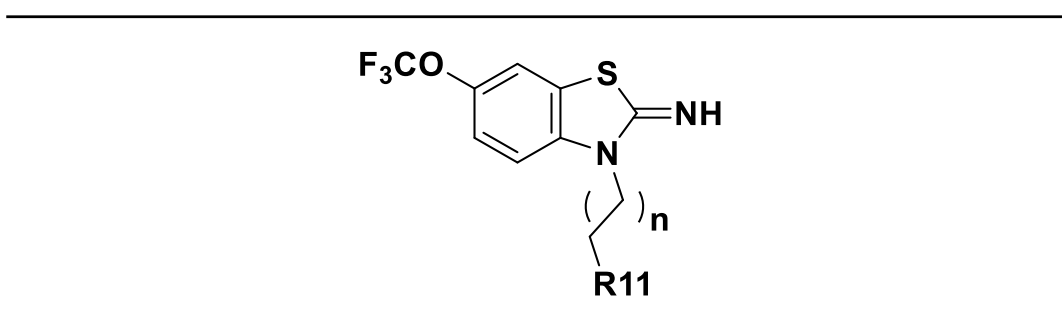

\begin{tabular}{|c|c|c|c|c|}
\hline \multirow{2}{*}{ Compound } & \multirow{2}{*}{$-\mathbf{R}_{11}$} & \multirow{2}{*}{$\mathbf{n}$} & Glu $^{a}$ & H.H. ${ }^{b}$ \\
\hline & & & \multicolumn{2}{|c|}{$\mathrm{ED}_{50}(\mathrm{mg} / \mathrm{kg} \mathrm{ip})$} \\
\hline I & -SMe & 0 & 1.0 & 14.0 \\
\hline II & -SOMe & 1 & 1.1 & 5.5 \\
\hline III & $-\mathrm{SO}_{2} \mathrm{Me}$ & 1 & 1.8 & $2.5-10$ \\
\hline IV & $-\mathrm{NMe}_{2}$ & 1 & 2.3 & 4.0 \\
\hline $\mathbf{V}$ & & 1 & 2.0 & $<5$ \\
\hline VI & & 1 & 3.0 & $2.5-10$ \\
\hline VII & & 1 & 2.2 & $2.5-10$ \\
\hline VIII & & 1 & 3.5 & 5.5 \\
\hline riluzole & & & 3.2 & 4.0 \\
\hline
\end{tabular}

${ }^{a}$ Protection against glutamic acid-evoked convulsions in rats. Variability: 15 and $25 \%$. ${ }^{\mathrm{b}}$ Protective effect against mortality induced by hypobaric hypoxia in mice. Variability: $20 \%$.

A significantly enhanced antiglutamatergic activity was obtained by the introduction of sulfur- or nitrogen-containing 3-substituents. The most potent derivatives were 2 -imino-3-(2-methylthio)- and 2-imino-3-(2-methylsulfinyl)ethyl-6-trifluoromethoxybenzothiazolines (II and III, respectively). The introduction of piperidine (V), 4-phenylpiperidine (VI), 4-phenyl-1,2,3,6-tetrahydropyridine (VII) and 4-phenylpiperazine (VIII) linked with an ethyl chain in position 3 afforded potent neuroprotective compounds similar to riluzole.

In 2007, Gunakkunru and Verma described interesting studies about the quantitative structure-activity relationship of riluzole series from the Mignani's team results (vide supra) [65]. From 24 riluzole analogues (2-benzothiazolamines and 3-substituted-2-imino benzothiazolines), QSAR models were developed. The descriptors used in this study were: polarizability, density, molar refractivity, molar volume, average mass, and parachor, as well regression data and cross validation parameters. The 3-substituted iminobenzothiazolines can be modeled remarkably using index of refraction, surface tension, and average mass. 
Post etiam, in 2018, Sweeney et al. described the synthesis of triazole-containing riluzole analogues and their neuroprotective effects. [56] The 49 compounds prepared were chemically close to the 6-substituted-2-benzothiazolamines (e.g., VI, VII and VIII) described in Figure 9, and were prepared using click reaction. Within this library, seven compounds, excluding riluzole, attenuated kainate-induced neurofilament loss, and together with riluzole resulted positive in the MAPS assay in primary cortical neurons. The compounds IX and $\mathbf{X}$ (Figure 9) displayed the greatest effect.

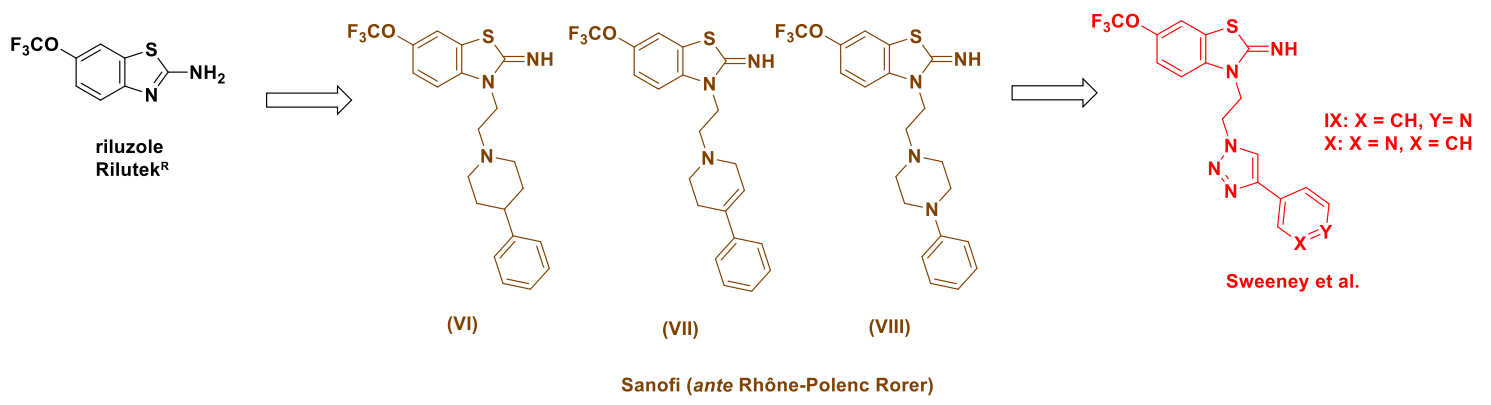

Figure 9. Chemical structures of the most potent hybrids of riluzole (VI, VII, VIII, IX and X).

\section{Pifithrin- $\alpha$ with Neuroprotective Properties}

Pifithrin (PFT)- $\alpha$ contains a partially saturated bicyclic thiazolyl core (Scheme 3 ). It is a p53 inhibitor preventing neuronal cell death by inhibiting p53 transcriptional activity, mitochondrial damage, and caspase activation. PTF $\alpha$ showed neuroprotective effects against traumatic brain injury in the striatum through suppression of neuroinflammation, oxidative stress, autophagy, and apoptosis [66]. PTF $\alpha$ was effective for the neuronal cell protection reducing the side effects of anticancer drugs. Zhu et al. showed that PTF $\alpha$ and several close analogues (XI, XII and XIII) exhibited neuroprotective activity in tissue cultures such as in PC12 and hippocampal cells from camptothecin-induced cell death [66]. In vivo, PTF displayed neuroprotection in transient and permanent stroke mouse models at the dose of $2 \mathrm{mg} / \mathrm{kg}$ ip.

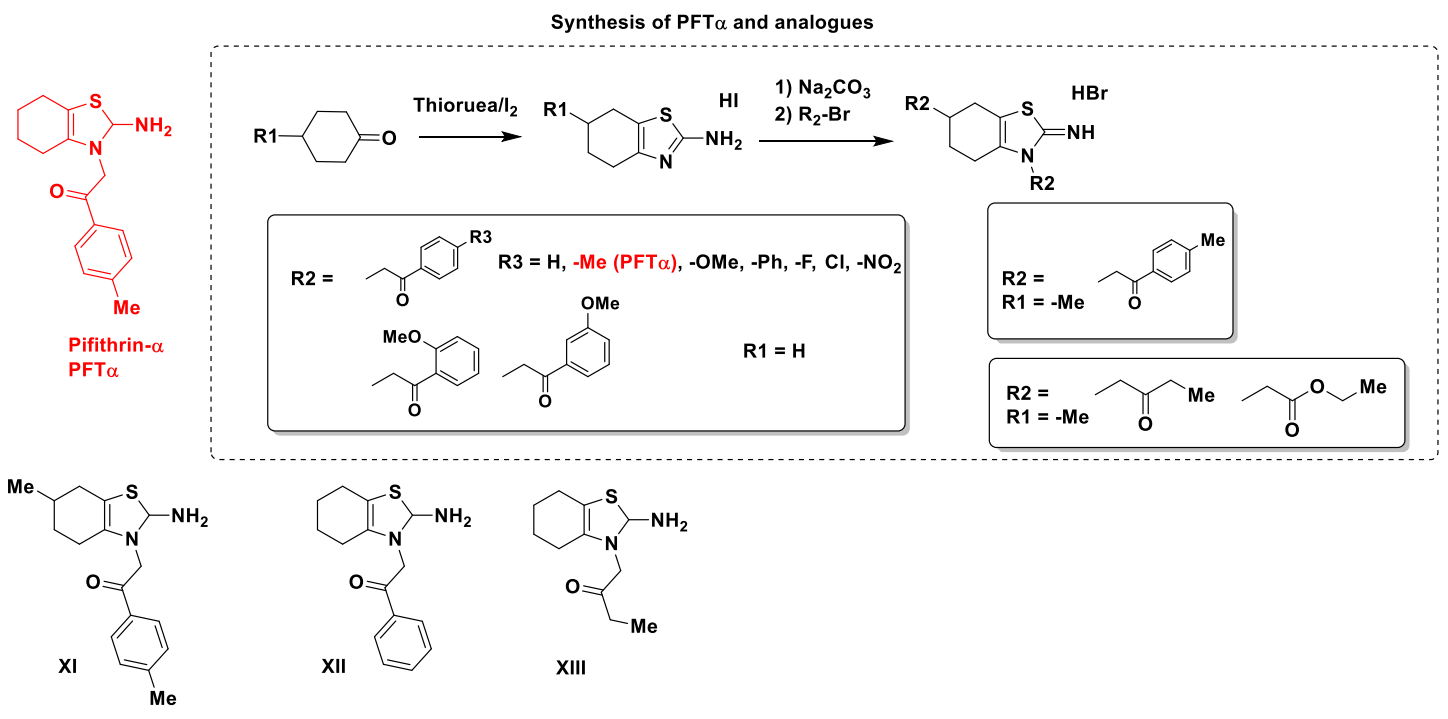

Scheme 3. Chemical structures of pifithrin- $\alpha$, XI, XII, XII and their synthetic pathway.

\section{Dexpramipexole for the Treatment of ALS}

The benzothiazolamine (-)-pramipexole (S-configuration, Mirapex ${ }^{\circledR}$; also named PPX) is a medication indicated for the treatment of Parkinson's disease and the restless legs syndrome. PPX enantiomer dexpramipexole [KNS-760704, (6R)-(+)-4,5,6,7-tetrahydro- $N$-propyl-2,6-benzo-thiazolediamine 
dihydrochloride; also named BIIB 050 or RPPX] has been found to be a good neuroprotective agent in vitro and in several animal models, and may therefore be of interest for the treatment of ALS (Figure 10) [67].

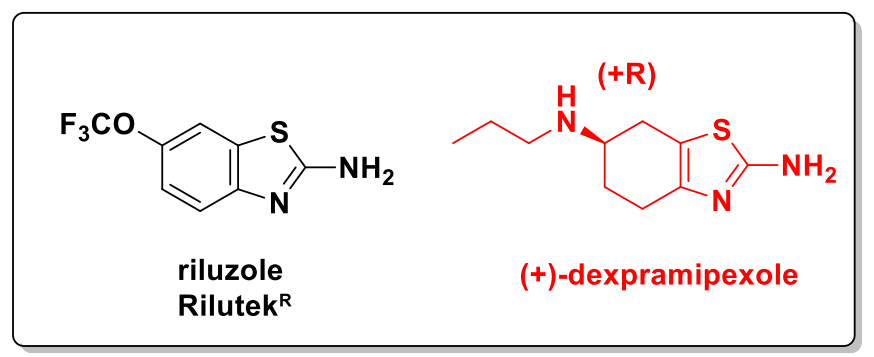

Amyotropic lateral sclerosis (ALS) treatment

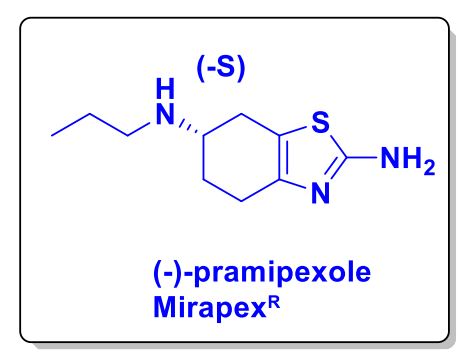

Parkinson disease treatment

Figure 10. Chemical structures of riluzole, dexpramipexole, and (-)-pramipexole.

Dexpramipexole was first recognized as a potential drug against ALS by several groups such as Ferrari-Toninelli et al. [68], who described that both (-)-pramipexole and dexpramipexole showed antioxidant and neuroprotective activity, independent of chirality using neuroblastoma cells. Equipotent efficacy in preventing cell death induced by $\mathrm{H}_{2} \mathrm{O}_{2}$ and inhibiting mitochondrial reactive oxygen species generation were observed.

Dexpramipexole is a weak nonergoline dopamine agonist, and unlike its $S$-isomer (-)-pramipexole, displays agonist activity on dopamine D2, D3, and D4 receptors. It also exhibited significant neuroprotective properties independent of its dopamine receptor agonism [69]. Very recently and similarly to riluzole, it was shown to inhibit voltage-gated Nav1.8 sodium channels and provide analgesia in various nociceptive and neuropathic pain models [70,71]. (-)-Pramipexole (Mirapex ${ }^{\circledR}$ ) was developed by Boehringer Ingelheim (Ridgefield, CT, USA) and was approved by the US FDA in 1997 and by the European Medicines Agency (EMA) in 1998. (-)-Pramipexole is used orally for the treatment of idiopathic Parkinson's disease and represents a novel class of nonergot selective dopamine receptor agonists. Mirapex®is used as monotherapy and as adjunctive therapy with levodopa [72]. An interesting study has been described by Javan et al. regarding the in vitro long-acting formulation for (-)-pramipexole based on poly(3-hydroxybutyrate-co-3-hydroxy-valerate) nanoparticles. (-)-Pramipexole is included inside the matrix of the polymer, and it is gradually released within 30 days [73]. In addition, several studies highlighted the therapeutic use of (-)-pramipexole for the treatment of cognitive disorders [74].

An interesting study regarding the repurposing of dexpramipexole in neonatal hypoxic/ischemic encephalopathy has been highlighted. It was shown that dexpramipexole at the dose of $3 \mathrm{mg} / \mathrm{kg}$ (b.i.d., ip), after the hypoxic insult due to distal middle cerebral artery occlusion, decreased the infarction size in pups with mild to moderate injuries [75].

Compared to the $S$-isomer (-)-pramipexole, for which stereospecific dopamine receptor affinity difference was observed, dexpramipexole has a much lower dopamine agonist activity. Nevertheless, using nondopaminergic JK cells in cell-based assays, similar specific biological effects were observed for the two enantiomers: both: 1) reduced the production of reactive oxygen species (ROS), 2) decreased the activation of apoptotic pathways, and 3) increased cell survival in response to a variety of neurotoxins such as glutamate. Both enantiomers were shown to enter the brain with a brain-to-plasma ratio in excess of 6 in mice. At a lower dose, (-)-pramipexole administration was associated with a significantly increased wheel-running behavior attributed to dopaminergic activation. Consequently, $(-)$-pramipexole has a limited clinical utility as a neuroprotective agent due to its unacceptable dopaminergic side effects, including hypotension and seizures, but is currently used to treat symptoms of Parkinson's disease. Unlike (-)-pramipexole, dexpramipexole that displays similar neuroprotective activity but limited dopaminergic agonism, could be used in the treatment of ALS. The exact mode of 
action of dexpramipexole is unknown, but it showed a neuroprotective effect on neurons under stress within motor neuron cells [76].

Importantly, the lack of significant D2 dopamine receptor activation of dexpramipexole could allow for theoretically reaching much higher drug levels in CNS. Physicochemical, pharmacokinetic (PK/PD), and toxicokinetic profiles of dexpramipexole in preclinical studies were performed. Dexpramipexole is highly water-soluble ( $>600 \mathrm{mg} / \mathrm{mL})$, highly stable in solution in water as well in physiological buffer solutions, and it is not hygroscopic. Dexpramipexole is neither mutagenic nor genotoxic, did not significantly affect the cardiac delayed rectifier (hERG) potassium current, and in a good laboratory practices (GLP) study, showed good cardiovascular safety in Gottingen minipigs. No adverse effects were observed at the highest dose tested $(75 \mathrm{mg} / \mathrm{kg})$. In order to get IND approval, acute and chronic toxicology studies have been fully completed (in rats and minipigs) and clearly showed that dexpramipexole could be developed for ALS treatment.

The preparation of (-)-pramipexole occurred via the resolution of racemic ( \pm )-pramipexole [77] or using preparative chiral chromatography to separate (-)-pramipexole and dexpramipexole [78], but these processes are long and tedious. Consequently, an asymmetric synthesis was performed. The scalable synthetic pathway and resolution of (-)-pramipexole was presented by Zivec et al. [79] as an industrially acceptable process and also, previously, by Schneider and Mierau (Scheme 4) [80]. (-)-Pramipexole was first described in the European patent application EP 0186087.

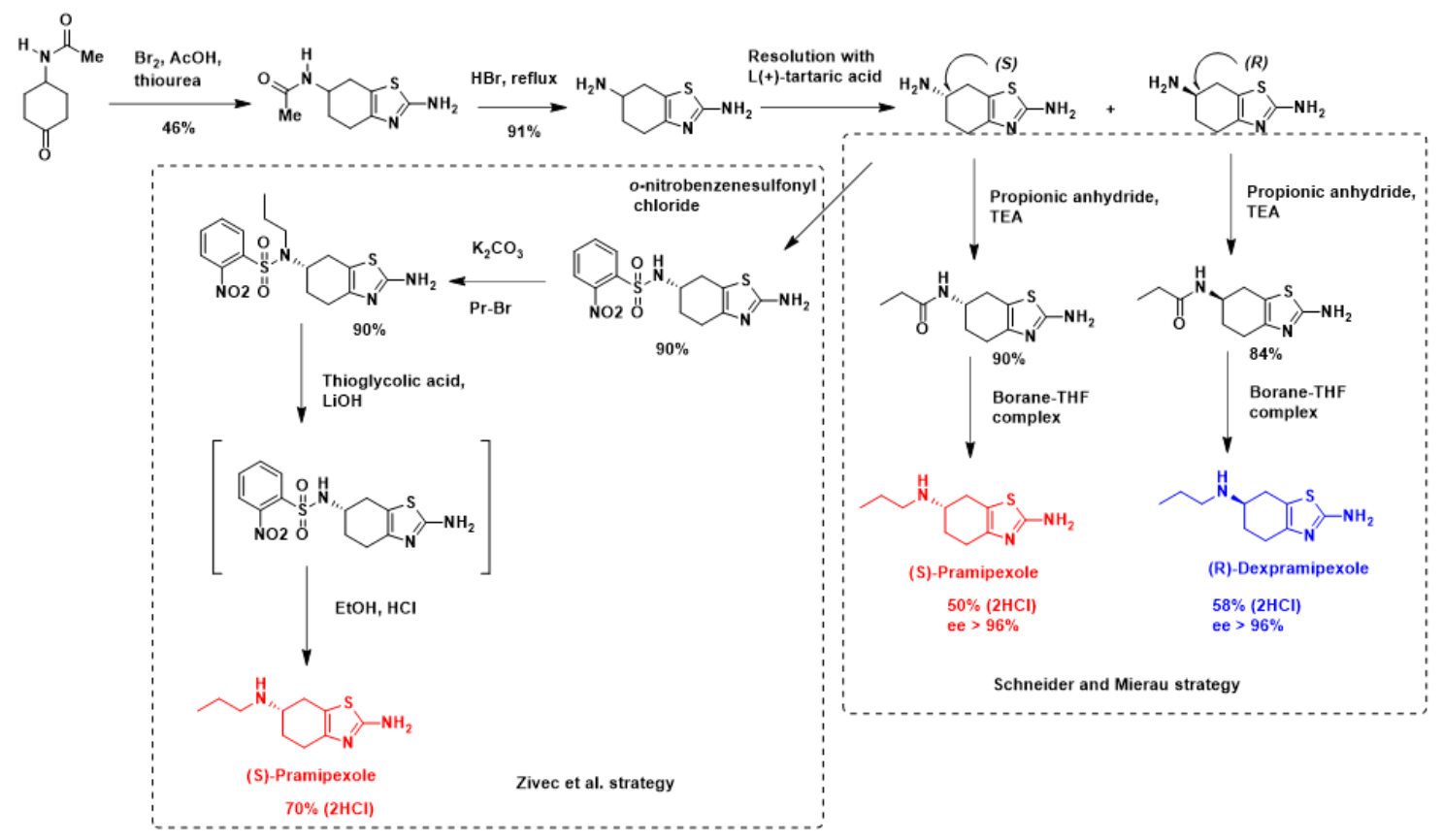

Scheme 4. Synthesis of (S)-pramipexole and dexpramipexole using the optical resolution strategy.

Interestingly, Ferraboschi et al. described the preparation of (-)-pramipexole and dexpramipexole using baker's yeast based on the highly stereoselective transformation allowed by these biocatalysts (Scheme 5) [81]. 


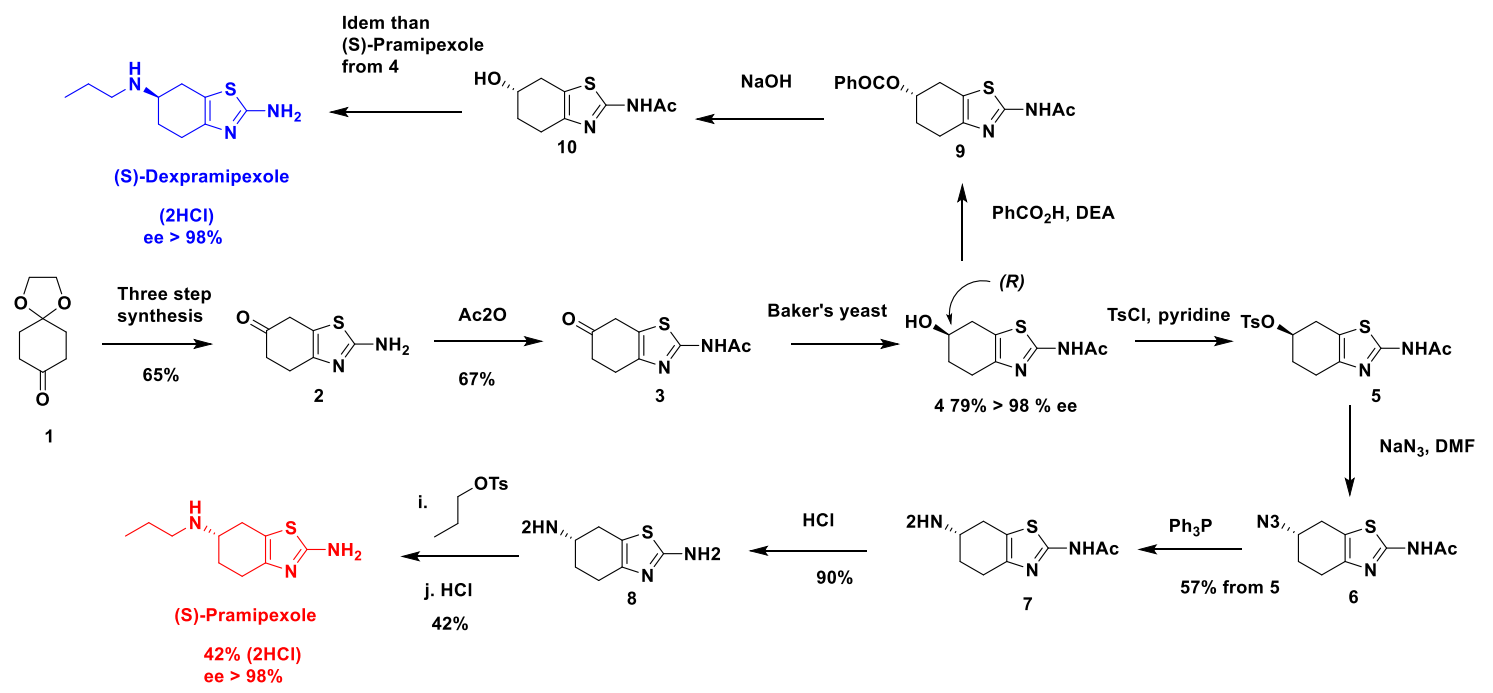

Scheme 5. Synthesis of (-)-pramipexole and dexpramipexole using the biocatalyst strategy.

\subsection{Clinical Trials of Dexpramipexole for the Treatment of ALS}

Dexpramipexole has been investigated in clinical trials for ALS by Knopp Biosciences (Pittsburgh, PA, USA) and Biogen Idec (Cambridge, MA, USA). In 2004, dexpramipexole was introduced into phase I based on new drug application acceptance (IND 60,948) by James Bennett at the University of Virginia (Charlottesville, VA, USA). Fifteen ALS patients received escalated dosing from 1.5 to $30 \mathrm{mg} /$ day, where no complications were observed, and then continued to $30 \mathrm{mg} /$ day for an additional eight weeks. Based on these results, clinical efficacy studies of the $30 \mathrm{mg} /$ day dose were started in September 2005, and the dose-escalation study from 30 to $300 \mathrm{mg} /$ day was initiated in January 2006. In September 2009, the FDA gave a fast track designation for the development of dexpramipexole for ALS [82], and it has received orphan drug designation by both the FDA and the EMA.

Based on the excellent tolerability of higher doses of dexpramipexole (phase I), initial phase II dosing experiments were advanced. In a futility design study, the dose of $30 \mathrm{mg} /$ day of dexpramipexole was orally administrated ( $n=30$ patients) to evaluate its therapeutic efficacy. Analysis of the data showed individual declines in the standard measure of disability in ALS, named the ALS functional rating scale (ALSFRS-R) and neurophysiological index (NI) values, but with nonsignificant reductions during treatment. Consequently, dosing with $30 \mathrm{mg} /$ day of dexpramipexole did not induce clinically meaningful effects on ALS progression. Then, in a dose-escalation study, excellent safety and tolerability after oral administration were also observed up to a maximum daily dose of $100 \mathrm{mg}$ three times a day (TID) without dopaminergic side-effects (e.g., discernible effects, QTc intervals). The trough and peak of the drug increased linearly with dosing ( 30 to $300 \mathrm{mg} /$ day dose-escalation study). Observation of $60 \mathrm{mg} /$ day induced a small slowing of decline in ALSFRS-R scores but was not significant in the small population included in the clinical studies. Excellent safety and tolerability of oral administration of dexpramipexole up to $300 \mathrm{mg} /$ day were observed based on one year of cumulative dosing, as well as extensive distribution into body tissue stores; there was statistically nonsignificant improvements at 30 and $60 \mathrm{mg} /$ day dosing. These results supported the long-term testing of higher dexpramipexole doses to treat ALS [83].

In order to confirm safety at a range of doses and to determine if there was still an efficacy signal with double-blind treatment, a phase II clinical development of dexpramipexole in subjects with ALS was also advanced in two different and consecutive parts (1 and 2), double-blind safety and tolerability studies based on its effects on the decrease of the disease and mortality for dose selection studies. Dr. Cudkowicz and colleagues directed these clinical studies from the Northeast ALS Consortium, a nationwide ALS clinical trial group [84]. In part 1, dexpramipexole was administered 50, 150 or $300 \mathrm{mg} /$ day orally every $12 \mathrm{~h}$ vs. randomized placebo over 12 weeks $(\mathrm{n}=102$ newly diagnosed ALS 
patients, familial or sporadic ALS, in 20 US sites). In part 2, patients who completed all 12 weeks of part 1 were eligible for randomization in part 2, after a 4-week, single-blind placebo washout strategy, followed by randomized, double-blind, active treatment for 24 weeks ( $50 \mathrm{mg} /$ day or $300 \mathrm{mg} /$ day). The primary outcome was the safety, whereas the secondary outcomes were safety, the changes in ALSFRS-R, vital capacity, cystatin C, and neurofilament H. Generally speaking, dexpramipexole was safe and well-tolerated. Dose-dependent attenuation of the slope of the decline of ALS was observed in part 1, and a significant difference between groups and mortality was observed in part 2.

In summary, in phase II trials dexpramipexole ( 25 to $150 \mathrm{mg}$ b.i.d.) was well tolerated for up to 9 months and showed a significant benefit at the high dose in a combined assessment of function and mortality in patients with amyotrophic lateral sclerosis.

Dexpramipexole was then investigated by Knopp Biosciences and Biogen Idec for the treatment of ALS in a randomized, double-blind, phase III trial. The objective of this study was to evaluate whether dexpramipexole (oral tablet, $150 \mathrm{mg}$ twice daily for up to 18 months) was safe and effective in the treatment of ALS. In 2011, two clinical trials were started with a total of 1,549 patients (familial or sporadic ALS) in multi-international centers. Dexpramipexole was generally well tolerated but did not differ from placebo on any specified efficacy endpoint measurement. The drug failed to show efficacy in terms of function or survival of patients with ALS.

\subsection{Recent Additional in vivo Studies of Dexpramipexole for the Treatment of ALS}

In 2014, Vieira et al. reported the non-effectiveness of dexpramipexole in two in vivo models of ALS-related neurodegeneration [72]. In the past two decades, important advances have been made in the identification of genes that predispose individuals to develop inherited ALS; for instance: 1) SOD1 was the first gene to be identified as causing ALS when mutated; 2) identification of neuronal cytoplasmic $43 \mathrm{kDa}$ Tar DNA binding protein (TDP43). This protein is a prominent pathological hallmark in both familial and sporadic ALS; mutations in the gene were identified in familial cases of ALS. The two in vivo parallel screening systems were based on: 1) sibling-matched, gender-balanced survival efficacy screening in high-copy B6-SJL-SOD1G93A/Gur1 mice, and 2) neuronal survival screening in primary rat cortical neurons transfected with wildtype human TDP43 or mutant human TDP43. Dexpramipexole was administered approximatively at the levels used in the phase II clinical trial. No difference between the control and experimental conditions was observed in both in vivo studies.

\subsection{Clinical Trials of Dexpramipexole for the Treatment of Asthma}

In addition to the research on ALS, dexpramipexole also was found to significantly decrease absolute eosinophil counts (AECs), and this opened up opportunities to use it against hypereosinophilic syndromes (HESs) [85]. The HESs are a heterogeneous group of disorders characterized by peripheral eosinophilia and eosinophil-related end-organ damage. Interestingly, as a proof-of-concept study, dexpramipexole was evaluated in a phase II open-label trial and showed a reduced eosinophil count and eliminated the need for corticosteroid treatment in a subset of patients with steroid-responsive HESs. Dexpramipexole was orally administered twice daily $(150 \mathrm{mg})$. Bone marrow biopsy samples after 12 weeks of dexpramipexole showed selective absence of mature eosinophils in responders. Dexpramipexole appeared promising as a glucocorticoid (GC)-sparing agent without apparent toxicity in a subset of subjects with GC-responsive HESs. Knopp Biosciences is advancing the drug in both HESs and eosinophilic asthma [86].

\section{Conclusions and Perspectives}

Efforts to uncover better treatments to slow down, stop, or reverse neurodegeneration in ALS continue to be considered to treat this challenging disease; however no effective treatment is currently available. Research into ALS has been marked by successive failures in all clinical trials since riluzole was first marketed. In this review, we analyzed the development of dexpramipexole, including clinical trials as well the analogues of riluzole (substituted-benzothiazole derivatives) and Pifithrin- $\alpha$ 
as neuroprotectors. This analysis represents an interesting case study for a scientist working in the CNS domain in general and neuroprotection in particular, such as ALS. In light of the favorable safety profile of dexpramipexole in humans, this drug might have a realistic translational potential to treat other disorders, including other rare diseases.

Due to the key role played by several modified benzothiazolamines, their corresponding low molecular weight, and the importance of the nature of the substituents grafted on the benzothiazole structure, it might be of great interest to prepare the corresponding benzothiazole substituted at different positions of their backbone. For example, the introduction of phosphonate or phosphino groups may be envisaged, and this in turns would allow to prepare different complexes (e.g., Au, Ru, Ir, Pd) with the possibility to enhance the activity of benzothiazolamines or to open new perspectives in medicinal chemistry (Figure 11) [87,88].<smiles>Nc1nc2c(s1)=C=C=C=2</smiles><smiles>[R2]c1cnc(N)s1</smiles><smiles>[R2]CC1CCCCC1</smiles>

Ru, Ir, Au, Pd and Pt complexes $\mathbf{n}=0,1$ and 2

Figure 11. Chemical structures of modified benzothiazolamines.

It is also worth to note that the variability of the clinical symptoms and biological factors of this pathology justify the development of a personalized therapeutic approach for future clinical trials in the ALS field. In addition, in the personalized medicine field to treat patients with ALS, data from the literature suggest that there is a metabolic defect in ALS. This alteration corresponds to an increase in metabolism (the hypermetabolic pathway), and this dysfunction concerns the metabolism of lipids and carbohydrates, as well as disturbances in the mitochondrial function. Analysis of the metabolic profile of each patient with ALS should be an opportunity to tackle ALS based on personalized medicine, a point highlighted by Vandoorne et al. [89]. Following this direction, based on international collaborative efforts, population-based studies are clearly needed to gain a better estimate of the ALS burden, and as well, the understanding of ALS risk factors. The development of drugs based on metabolic approaches is a hope for treating this disease.

Finally, 2-aminobenzothiazole derivatives may be exploited as fragments in fragment-based approach strategy to find new active agents as described recently by Alnabulsi et al. in the discovery of amino-carboxamide benzothiazoles as potential lysine specific demethylase enzyme LSD1 inhibitors [90].

Author Contributions: All the authors contributed equally. All authors have read and agreed to the published version of the manuscript.

Funding: S. Mignani acknowledges the support of FCT-Fundação para a Ciência e a Tecnologia (Base Fund UIDB/00674/2020 and Programmatic Fund UIDP/00674/2020, Portuguese Government Funds) and ARDITI-Agência Regional para o Desenvolvimento da Investigação Tecnologia e Inovação through the project M1420-01-0145-FEDER-000005-CQM+ (Madeira 14-20 Program). S. Mignani and J-P. Majoral acknowledge transnational EuroNanoMed III funded projects including a proper acknowledgement of ERANET EuroNanoMed III and the respective funding partner organizations. J. P. Majoral thanks CNRS (France) for financial support. J.F Desaphy acknowledges the support of Association Française contre les Myopathies (grant \#19027).

Conflicts of Interest: The authors declare no conflict of interest. 


\section{References}

1. Garg, V.; Maurya, R.K.; Thanikachalam, P.V.; Bansal, G.; Monga, V. An insight into the medicinal perspective of synthetic analogs of indole: A review. Eur. J. Med. Chem. 2019, 180, 562-612.

2. Kumari, A.; Singh, R.K. Medicinal chemistry of indole derivatives: Current to future therapeutic prospectives. Bioorg. Chem. 2019, 89, 103021. [CrossRef]

3. Wishart, D.S.; Feunang, Y.D.; Guo, A.C.; Lo, E.J.; Marcu, A.; Grant, J.R.; Sajed, T.; Johnson, D.; Li, C.; Sayeeda, Z.; et al. DrugBank 5.0: A major update to the DrugBank database for 2018. Nucleic Acids Res. 2018, 46, D1074-D1082. [CrossRef] [PubMed]

4. Cerveri, A.; Bandini, M. Recent advances in the catalytic functionalization of "electrophilic" indoles. Chin. J. Chem. 2020, 38, 287-294. [CrossRef]

5. Troy, D.; Hubbard, T.D.; Murray, I.A.; Perdew, G.H. Indole and Tryptophan Metabolism: Endogenous and Dietary Routes to Ah Receptor Activation. Drug Metab. Dispos. 2015, 43, 1522-1535.

6. Baell, J.B.; Holloway, G.A. New substructure filters for removal of pan assay interference compounds (PAINS) from screening libraries and for their exclusion in bioassays. J. Med. Chem. 2010, 53, 2719-2740. [CrossRef] [PubMed]

7. Dvořák, Z.; Kopp, F.; Costello, C.M.; Kemp, J.S.; Li, H.; Vrzalová, A.; Štěpánková, M.; Bartoňková, I.; Jiskrová, E.; Poulíková, K. Targeting the pregnane $\mathrm{X}$ receptor using microbial metabolite mimicry. EMBO Mol. Med. 2020, 12, e11621. [CrossRef]

8. Lazzara, P.R.; Moore, T.W. Scaffold-hopping as a strategy to address metabolic liabilities of aromatic compounds. RSC Med. Chem. 2020, 11, 18-29. [CrossRef]

9. Roughley, S.D.; Jordan, A.M. The medicinal chemist's toolbox: An analysis of reactions used in the pursuit of drug candidates. J. Med. Chem. 2011, 54, 3451-3479. [CrossRef]

10. Filz, O.A.; Poroikov, V.V. Fragment-based lead design. Russian Chem. Rev. 2012, 81, 158-174. [CrossRef]

11. Mishra, C.B.; Kumari, S.; Tiwari, M. Thiazole: A promising heterocycle for the development of potent CNS active agents. Eur. J. Med. Chem. 2015, 92,1-34. [CrossRef]

12. Naga Raju, G.; Karumudi, B.S.; Rao, N.R. enzothiazole-Versatile heterocyclic nucleus in medicinal chemistry: A review. B. Int. J. Pharm. Chem. 2015, 5, 104-111.

13. Gleeson, M.P. Generation of a set of simple, interpretable ADMET rules of thumb. J. Med. Chem. 2008, 51, 817-834. [CrossRef] [PubMed]

14. Gualdani, R.; Tadini-Buoninsegni, F.; Roselli, M.D.I.; Contino, M.; Colabufo, N.A.; Lentini, G. Inhibition of hERG potassium channel by the antiarrhythmic agent mexiletine and its metabolite m-hydroxymexiletine. Pharmacol. Res. Perspect. 2015, 3, e00160. [CrossRef] [PubMed]

15. Yildiz-Oren, I.; Yalcin, I.; Ki-Sener, E.; Ucarturk, N. Synthesis and structure-activity relationships of new antimicrobial active multisubstituted benzazole derivatives. Eur. J. Med. Chem. 2004, 39, 291-298. [CrossRef] [PubMed]

16. Verma, A.K.; Martin, A.; Singh, A.K. Synthesis, characterization and evaluation of anti-inflammatory and analgesic activity of benzothiazole derivatives. Indian J. Pharm. Biol. Res. 2014, 2, 84-89. [CrossRef]

17. Spillane, C.B.; Fletcher, N.C.; Rountree, S.M.; van Den, B.H.; Chanduloy, S.; Morgan, J.L.; Keene, F.R. Benzothiazole bipyridine complexes of ruthenium(II) with cytotoxic activity. J. Biol. Inorg. Chem. 2007, 12, 797-807. [CrossRef]

18. Desaphy, J.-F.; Carbonara, R.; Costanza, T.; Conte Camerino, D. Preclinical evaluation of marketed sodium channel blockers in a rat model of myotonia discloses promising antimyotonic drugs. Exp. Neurol. 2014, 255, 96-102. [CrossRef]

19. Amnerkar, N.D.; Bhusari, K.P. Synthesis, Anticonvulsant Activity and 3D-QSAR Study of Some prop-2-eneamido and 1-acetyl-pyrazolin Derivatives of Aminobenzothiazole. Eur. J. Med. Chem. 2010, 45, 149-159. [CrossRef]

20. Plesnila, N.; Von, B.L.; Retiounskaia, M.; Engel, D.; Ardeshiri, A.; Zimmermann, R.; Hoffmann, F.; Landshamer, S.; Wagner, E.; Culmsee, C. Delayed neuronal death after brain trauma involves p53-dependent inhibition of NF-kappaB transcriptional activity. Cell. Death Differ. 2007, 14, 1529-1541. [CrossRef]

21. Albert, A. Chemical aspects of selective toxicity. Nature 1958, 182, 421-423. [CrossRef] [PubMed]

22. Mignani, S.; Huber, S.; Tomás, H.; Rodrigues, J.; Majoral, J.-P. Compound high-quality criteria: A new vision to guide the development of drugs, current situation. Drug Discov. Today 2016, 21, 573-584. [CrossRef] 
23. Cavalluzzi, M.M.; Mangiatordi, G.F.; Nicolotti, O.; Lentini, G. Ligand efficiency metrics in drug discovery: The pros and cons from a practical perspective. Exp. Opin. Drug Discv. 2017, 12, 1087-1104. [CrossRef] [PubMed]

24. Lipinski, C.A.; Lombardo, F.; Dominy, B.W.; Feeney, P.J. Experimental and computational approaches to estimate solubility and permeability in drug discovery and development settings. Adv. Drug Deliv. Rev. 1997, 23, 3-25. [CrossRef]

25. Veber, D.F.; Johnson, S.R.; Cheng, H.Y.; Smith, B.R.; Ward, K.W.; Kopple, K.D. Molecular Properties That Influence the Oral Bioavailability of Drug Candidates. J. Med. Chem. 2002, 45, 2615-2623. [CrossRef] [PubMed]

26. Ghose, A.K.; Viswanadhan, V.N.; Wendoloski, J.J.A. Knowledge-based approach in designing combinatorial or medicinal chemistry libraries for drug discovery. 1. A qualitative and quantitative characterization of known drug databases. J. Comb. Chem. 1999, 1, 55-68. [CrossRef] [PubMed]

27. Oprea, T.I. Property distribution of drug-related chemical databases. J. Comput. Aided Mol. Des. 2000, 14, 251-264. [CrossRef]

28. Congreve, M.; Carr, R.; Murray, C.; Jhoti, H. A "rule of three" for fragment-based lead discovery? Drug Discov. Today 2003, 8, 876-877. [CrossRef]

29. Lovering, F.; Bikker, J.; Humblet, C. Escape from flatland: Increasing saturation as an approach to improving clinical success. J. Med. Chem. 2009, 52, 6752-6756. [CrossRef]

30. Smith, D.A.; Di, L.; Kerns, E.H. The effect of plasma protein binding on in vivo efficacy: Misconceptions in drug discovery. Nat. Rev. Drug Discov. 2010, 9, 929-939. [CrossRef]

31. Liu, X.; Wright, M.; Hop, C.E.C.A. Rational Use of Plasma Protein and Tissue Binding Data in Drug Design. J. Med. Chem. 2014, 57, 8238-8248. [CrossRef] [PubMed]

32. Trainor, G.L. The importance of plasma protein binding in drug discovery. Exp. Opin. Drug Discov. 2007, 2, 51-64. [CrossRef] [PubMed]

33. Meanwell, N.A. Improving drug candidates by design: A focus on physicochemical properties as a means of improving compound disposition and safety. Chem. Res. Toxicol. 2011, 24, 1420-1456. [CrossRef] [PubMed]

34. de Lange, E.C.M.; van den Brink, W.; Yamamoto, Y.; de Witte, W.E.A.; Wong, Y.C. Novel CNS drug discovery and development approach: Model-based integration to predict neuro-pharmacokinetics and pharmacodynamics. Exp. Opin. Drug Discov. 2017, 12, 1207-1218. [CrossRef]

35. Dong, X.X.; Wang, Y.; Qin, Z.H. Molecular mechanisms of excitotoxicity and their relevance to pathogenesis of neurodegenerative diseases. Acta Pharmacol. Sin. 2009, 30, 379-387. [CrossRef]

36. Fernandez-Espejo, E. Pathogenesis of Parkinson's disease: Prospects of neuroprotective and restorative therapies. Mol. Neurobiol. 2004, 29, 15-30. [CrossRef]

37. Bonelli, R.M.; Wenning, G.K.; Kapfhammer, H.P. Huntington's disease: Present treatments and future therapeutic modalities. Int. Clin. Psychopharmacol. 2004, 19, 51-62. [CrossRef]

38. Ates, O.; Cayli, S.R.; Gurses, I.; Karabulut, A.B.; Yucel, N.; Kocak, A.; Cakir, C.O.; Yologlu, S. Do sodium channel blockers have neuroprotective effect after onset of ischemic insult? Neurol. Res. 2007, 29, 317-323. [CrossRef]

39. Bensimon, G.; Lacomblez, L.; Meininger, V.A. Controlled trial of riluzole in amyotrophic lateral sclerosis. ALS/Riluzole study group. N. Engl. J. Med. 1994, 330, 585-591. [CrossRef]

40. Bryson, H.M.; Fulton, B.; Benfield, P. Riluzole: A review of its pharmacodynamic and pharmacokinetic properties and therapeutic potential in amyotrophic lateral sclerosis. Drug Eval. 1996, 52, 549-563. [CrossRef]

41. Miller, R.G.; Mitchell, J.D.; Lyon, M.; Moore, D.H. Riluzole for amyotrophic lateral sclerosis (ALS)/motor neuron disease (MND). Cochrane Database Syst. Rev. 2002, 2, CD001447.

42. Hinchcliffe, M.; Smith, A. Riluzole: Real-world evidence supports significant extension of median survival times in patients with amyotrophic lateral sclerosis. Degener. Neurol. Neuromuscul. Dis. 2017, 7, 61-70. [CrossRef] [PubMed]

43. Dharmadasa, T.; Kiernan, M.C. Riluzole, disease stage and survival in ALS. Lancet Neurol. 2018, 17, 385-386. [CrossRef]

44. Enzmann, H. Withdrawal of Radicava, (Edaravone), $30 \mathrm{mg}$ Solution for Infusion-EMEA/H/C/004938/0000. Available online: https://www.ema.europa.eu/en/documents/withdrawal-letter/withdrawal-letter-radicava_ en.pdf (accessed on 24 May 2019). 
45. Camerino, G.M.; Fonzino, A.; Conte, E.; De Bellis, M.; Mele, A.; Liantonio, A.; Tricarico, D.; Tarantino, N.; Dobrowolny, G.; Musarò, A.; et al. Elucidating the contribution of skeletal muscle ion channels to amyotrophic lateral sclerosis in search of new therapeutic options. Sci. Rep. 2019, 9, 3185. [CrossRef] [PubMed]

46. Yacilla, G.; Sari, Y. Potential therapeutic drugs and methods for the treatment of amyotropic lateral sclerosis. Curr. Med. Chem. 2014, 21, 3583-3593. [CrossRef] [PubMed]

47. Doble, A. The pharmacology and mechanism of action of riluzole. Neurology 1996, 47, S233-S241. [CrossRef]

48. Martin, D.; Thompson, M.A.; Nadler, J.V. The neuroprotective agent riluzole inhibits release of glutamate and aspartate from slices of hippocampal area CA1. Eur. J. Pharmacol. 1993, 250, 473-476. [CrossRef]

49. Frizzo, M.E.; Dall'Onder, L.P.; Dalcin, K.B.; Souza, D.O. Riluzole enhances glutamate uptake in rat astrocyte cultures. Cell. Mol. Neurobiol. 2004, 24, 123-128. [CrossRef]

50. Schmidt, J.; Schmidt, T.; Golla, M.; Lehmann, L.; Weber, J.J.; Hübener-Schmid, J.; Riess, O. In vivo assessment of riluzole as a potential therapeutic drug for spinocerebellar ataxia type 3. J. Neurochem. 2016, 138, 150-162. [CrossRef]

51. Sala, G.; Arosio, A.; Conti, E.; Beretta, S.; Lunetta, C.; Riva, N.; Ferrarese, C.; Tremolizzo, L. Riluzole Selective Antioxidant Effects in Cell Models Expressing Amyotrophic Lateral Sclerosis Endophenotypes. Clin. Psychopharmacol. Neurosci. 2019, 17, 438-442. [CrossRef]

52. Hassanzadeh, K.; Habibi-asl, B.; Roshangar, L.; Nemati, M.; Ansarin, M.; Farajnia, S. Intracerebroventricular administration of riluzole prevents morphine-induced apoptosis in the lumbar region of the rat spinal cord. Pharmacol. Rep. 2010, 62, 664-673. [CrossRef]

53. Selin Üstün Bezgin, S.; Uygur, K.K.; Gökdoğan, C.; Elmas, C.; Göktaş, G. The effects of riluzole on cisplatin-induced ototoxicity. Int. Arch. Otorhinolaryngol. 2019, 23, e267-e275. [CrossRef] [PubMed]

54. Longinetti, E.; Fang, F. Epidemiology of amyotrophic lateral sclerosis: Anupdate of recent literature. Curr. Opin. Neurol. 2019, 32, 771-776. [CrossRef] [PubMed]

55. Jimonet, P.; Audiau, F.; Barreau, M.; Blanchard, J.-C.; Boireau, A.; Bour, Y.; Coleno, M.-A.; Doble, A.; Doerflinger, G.; Do Huu, C.; et al. Riluzole series. Synthesis and in vivo "antiglutamate" activity of 6-substituted-2-benzothiazolamines and 3-substituted-2-imino-benzothiazolines. J. Med. Chem. 1999, 42, 2828-2843. [CrossRef] [PubMed]

56. Sweeney, J.B.; Rattray, M.; Pugh, V.; Powell, L.A. Riluzole-triazole hybrids as novel chemical probes for neuroprotection in amyotrophic lateral sclerosis. ACS Med. Chem. Lett. 2018, 9, 552-556. [CrossRef]

57. Kalmar, B.; Lu, C.H.; Greensmith, L. The role of heat shock proteins in amyotrophic lateral sclerosis: The therapeutic potential of arimoclomol. Pharmacol. Ther. 2014, 141, 40-54. [CrossRef]

58. Akamatsu, M.; Yamashita, T.; Hirose, N.; Teramoto, S.; Kwak, S. The AMPA receptor antagonist perampanel robustly rescues amyotrophic lateral sclerosis (ALS) pathology in sporadic ALS model mice. Sci. Rep. 2016, 6, 28649. [CrossRef]

59. Cudkowicz, M.E.; Cudkowicz, M.E.; Sarah Titus, S.; Kearney, M.; Yu, H.; Sherman, A.; Schoenfeld, D.; Hayden, D.; Shui, A.; Brooks, B.; et al. Efficacy and safety of ceftriaxone for amyotrophic lateral sclerosis: Results of a multi-stage, randomised, double-blind, placebo-controlled, phase 3 study. Lancet Neurol. 2014, 13, 1083-1091. [CrossRef]

60. Nagata, E.; Ogino, M.; Iwamoto, K.; Kitagawa, Y.; Iwasaki, Y.; Yoshii, F.; Ikeda, J.E. Bromocriptine mesylate attenuates amyotrophic lateral sclerosis: A phase 2a, randomized, double-blind, placebo-controlled research in Japanese patients. PloS ONE 2016, 24, e0149509. [CrossRef]

61. Pasinetti, G. Treatment of Amyotrophic Lateral Sclerosis with Nimesulide. U.S. Patent 20060041022A1, 23 February 2006.

62. Goutman, S.A.; Savelieff, M.G.; Sakowski, S.A.; Feldman, E.L. Stem cell treatments for amyotrophic lateral sclerosis: A critical overview of early phase trials. Expert Opin. Investig. Drugs 2019, 28, 525-543. [CrossRef]

63. ALS. Available online: https://www.sciencedaily.com/releases/2018/05/180521131659.htm (accessed on 22 July 2020).

64. Domino, E.F.; Unna, K.R.; Kerwin, J. Pharmacological properties of benzazoles. I. Relationship between structure and paralyzing action. J. Pharmacol. Exp. Ther. 1952, 105, 486-497.

65. Gunakkunru, A.; Verma, S.M. Quantitative structure activity relationship of riluzole series as anticonvulsants. Asian J. Chem. 2007, 19, 2843-2849. 
66. Zhu, X.; Yu, Q.S.; Cutler, R.G.; Culmsee, C.W.; Holloway, H.W.; Lahiri, D.K.; Mattson, M.P.; Greig, N.H. Novel p53 inactivators with neuroprotective action: Syntheses and pharmacological evaluation of 2-imino-2,3,4,5,6,7-hexahydrobenzothiazole and 2-Imino-2,3,4,5,6,7-hexahydrobenzoxazole derivatives. J. Med. Chem. 2002, 45, 5090-5097. [CrossRef] [PubMed]

67. Gribkoff, V.K.; Bozik, M.E. KNS-760704 [(6R)-4,5,6,7-tetrahydro-N6-propyl-2,6-benzothiazole-diamine dihydrocholride monohydrate] for the treatment of amyatropic lateral sclerosis. CNS Neurosci. Ther. 2008, 14, 215-226. [CrossRef]

68. Ferrari-Toninelli, G.; Maccarinelli, G.; Uberti, D.; Buerger, E.; Memo, M. Mitochondria-targeted antioxidant effects of S(-) and R(+) pramipexole. BMC Pharmacol. 2010, 10, 2. [CrossRef] [PubMed]

69. Antonini, A.; Barone, P.; Ceravolo, R.; Fabbrini, G.; Tinazzi, M.; Abbruzzese, G. Role of pramipexole in the management of Parkinson's disease. CNS Drugs 2010, 24, 829-841. [CrossRef]

70. Farinato, A.; Altamura, C.; Desaphy, J.F. Effects of Benzothiazolamines on voltage-gated sodium channels. Handb. Exp. Pharmacol 2018, 246, 230-250.

71. Urru, M.; Muzzi, M.; Coppi, E.; Ranieri, G.; Buonvicino, D.; Camaioni, E.; Coppini, R.; Pugliese, A.M.; Tanaka, B.; Estacion, M.; et al. Dexpramipexole blocks Nav1.8 sodium channels and provides analgesia in multiple nociceptive and neuropathic pain models. Pain 2020, 161, 831-841. [CrossRef]

72. Vieira, F.G.; LaDow, E.; Moreno, A.; Kidd, J.D.; Thompson, K.; Gill, A.; Finkbeiner, S.; Perrin, S. Dexpramipexole is ineffective in two models of ALS related neurodegeneration. PLOS ONE 2014, 19, e91608.

73. Javan, N.B.; Omid, N.J.; Hasb, N.M.; Shirmard, L.R.; Rafiee-Tehrani, M.; Dorkoosh, F. Preparation, statistical optimization and in vitro evaluation of pramipexole prolonged delivery system based on (3-hydroxybutyrate-co-3-hydroxyvalerate nanoparticles. J. Drug Deliv. Sci. Technol. 2018, 44, 82-90. [CrossRef]

74. Trenkwalder, C.; Hening, W.A.; Montagna, P.; Oertel, W.H.; Allen, R.P.; Walters, A.S.; Costa, J.; Stiasny-Kolster, K.; Sampaio, C. Treatment of restless legs syndrome: An evidence-based review and implications for clinical practice. MoV. Disord. 2008, 23, 2267-22302. [CrossRef] [PubMed]

75. Muzzia, M.; Buonvicino, D.; Urru, M.; Ofani, L.; Chiarugi, A. Repurposing of dexpramipexole to treatment of neonatal hypoxic/ischemic encephalopathy. Neurosci. Lett. 2018, 687, 234-240. [CrossRef] [PubMed]

76. Pandya, R.S.; Zhu, H.; Li, W.; Bowser, R.; Friedlander, R.M.; Wang, X. Therapeutic neuroprotective agents for amyotrophic lateral sclerosis. Cell. Mol. Life Sci. 2013, 70, 4729-4745. [CrossRef] [PubMed]

77. Juarez, J.M.; Silva Guisasola, G.O. Method for the Resolution of 2-amino-6-propilamino-4,5,6,7 Tetrahydrobenzothiazol and Intermediate Compounds. WO Patent Application No. 2006120268A1, 16 November 2006.

78. Siesel, D.A.; Ramirez, C.; Meckler, H. Process for Preparing Chirality Pure 2-amino-6-(alkyl)amino-4,5,6,7-tetrahydrobenzothiazoles by Liquid Chromatographic Resolution. WO Patent Application No. 200612276A1, 2 February 2006.

79. Zivec, M.; Anzic, B.; Gobec, S. A novel scalable synthesis of pramipexole. Org. Process. Res. Dev. 2010, 14, 1125-1129. [CrossRef]

80. Schneider, C.S.; Mierau, J. Dopamine autoreceptor agonists: Resolution and pharmacological activity of 2,6-diaminotetrahydrobenzothiazole and an aminothiazole analogue of apomorphine. J. Med. Chem. 1987, 30, 494-498. [CrossRef]

81. Ferraboschi, P.; Ciceri, S.; Ciuffreda, P.; De Mieri, M.; Romano, D.; Grisenti, P. Baker's yeast catalyzed preparation of a new enathiomerically pure synthon of (S)-pramipexole and its enatiomer (dexpramipexole). Tetrahedron Asymmetry 2014, 25, 1239-1245. [CrossRef]

82. News and Events-KNOPP Bioscience. Available online: https://knoppbio.com/index.php?section=news\& subsection=news\&id $=56$ (accessed on 6 September 2017).

83. Wang, H.; Larriviere, K.S.; Keller, K.E.; Ware, K.A.; Burns, T.M.; Conaway, M.A.; Lacomis, D.; Pattee, G.; Philipps, L.H.; Solenski, N.J.Z.; et al. R(+)pramipexole as a mitochondrally focused neuroprotectant: Initial early phase studies in ALS. ALS 2008, 9, 50-58.

84. Cudkowicz, M.; Bozik, M.E.; Ingersoll, E.W.; Miller, R.; Mitsumoto, H.; Shefner, J.; Moore, D.H.; Schoenfeld, D.; Mather, J.L.; Archibald, D.; et al. The effects of dexpramipexole (KNS-760704) in individuals with amyotrophic lateral sclerosis. Nat. Med. 2011, 17, 1652-1666. [CrossRef] 
85. Panch, S.R.; Bozik, M.E.; Brown, T.; Makiya, M.; Prussin, C.; Archibald, D.G.; Hebrank, G.T.; Sullivan, M.; Sun, X.; Wetzler, L.; et al. Dexpramipexole as an oral steroid-sparing agent in hypereosinophilic syndromes. Blood 2018, 132, 501-509. [CrossRef]

86. Pharmaceutical Daily-Knopp Biosciences Enters Collaboration with Leading UK Investigators to Commence Phase 2 Clinical Trial of Dexpramipexole in Severe Eosinophilic Asthma. Available online: http://www.pharmaceuticaldaily.com/knopp-biosciences-enters-collaboration-with-leading-ukinvestigators-to-commence-phase-2-clinical-trial-of-dexpramipexole-in-severe-eosinophilic-asthma (accessed on 22 July 2020).

87. Majoral, J.P.; Zablocka, M.; Koprowski, M.; Hameau, A.; Shi, X.; Mignani, S.; Caminade, A.M. Design, complexing and catalytic properties of phosphorus thiazoles and benzothiazoles: A concise overview. New J. Chem. 2019, 43, 16785-16795. [CrossRef]

88. Majoral, J.P.; Zablocka, M.; Caminade, A.M.; Balczewski, P.; Shi, X.; Mignani, S. Interactions gold/phosphorus dendrimers.Versatile ways to hybrid organic-metallic macromolecules. Coord. Chem. Rev. 2018, 358, 80-91. [CrossRef]

89. Vandoorme, T.; De Bock, K.; Den Bosch, L. Energy metabolism in ALS: An underappreciated opportunity? Acta Neuropathol. 2018, 135, 489-509. [CrossRef] [PubMed]

90. Alnabulsi, S.; Al-Hurani, E.; Al-Shar'i, N.A.; El-Elimat, T. Amino-carboxamide benzothiazoles as potential LSD1 hit inhibitors. Part I: Computational fragment-based drug design. J. Mol. Graph. Model. 2019, 93, 107440. [CrossRef] [PubMed]

(C) 2020 by the authors. Licensee MDPI, Basel, Switzerland. This article is an open access article distributed under the terms and conditions of the Creative Commons Attribution (CC BY) license (http://creativecommons.org/licenses/by/4.0/). 